Portland State University

PDXScholar

\title{
Financing Mechanisms for Capacity Improvements at Interchanges
}

James G. Strathman

Portland State University

Elizabeth Simmons

Portland State University

Follow this and additional works at: https://pdxscholar.library.pdx.edu/trec_reports

Part of the Transportation Commons, Urban Studies Commons, and the Urban Studies and Planning Commons

Let us know how access to this document benefits you.

\section{Recommended Citation}

Strathman, James and Elizabeth Simmons. Financing Mechanisms for Capacity Improvements at Interchanges . OTREC-RR-10-07. Portland, OR: Transportation Research and Education Center (TREC), 2010. https://doi.org/10.15760/trec.34

This Report is brought to you for free and open access. It has been accepted for inclusion in TREC Final Reports by an authorized administrator of PDXScholar. Please contact us if we can make this document more accessible: pdxscholar@pdx.edu. 

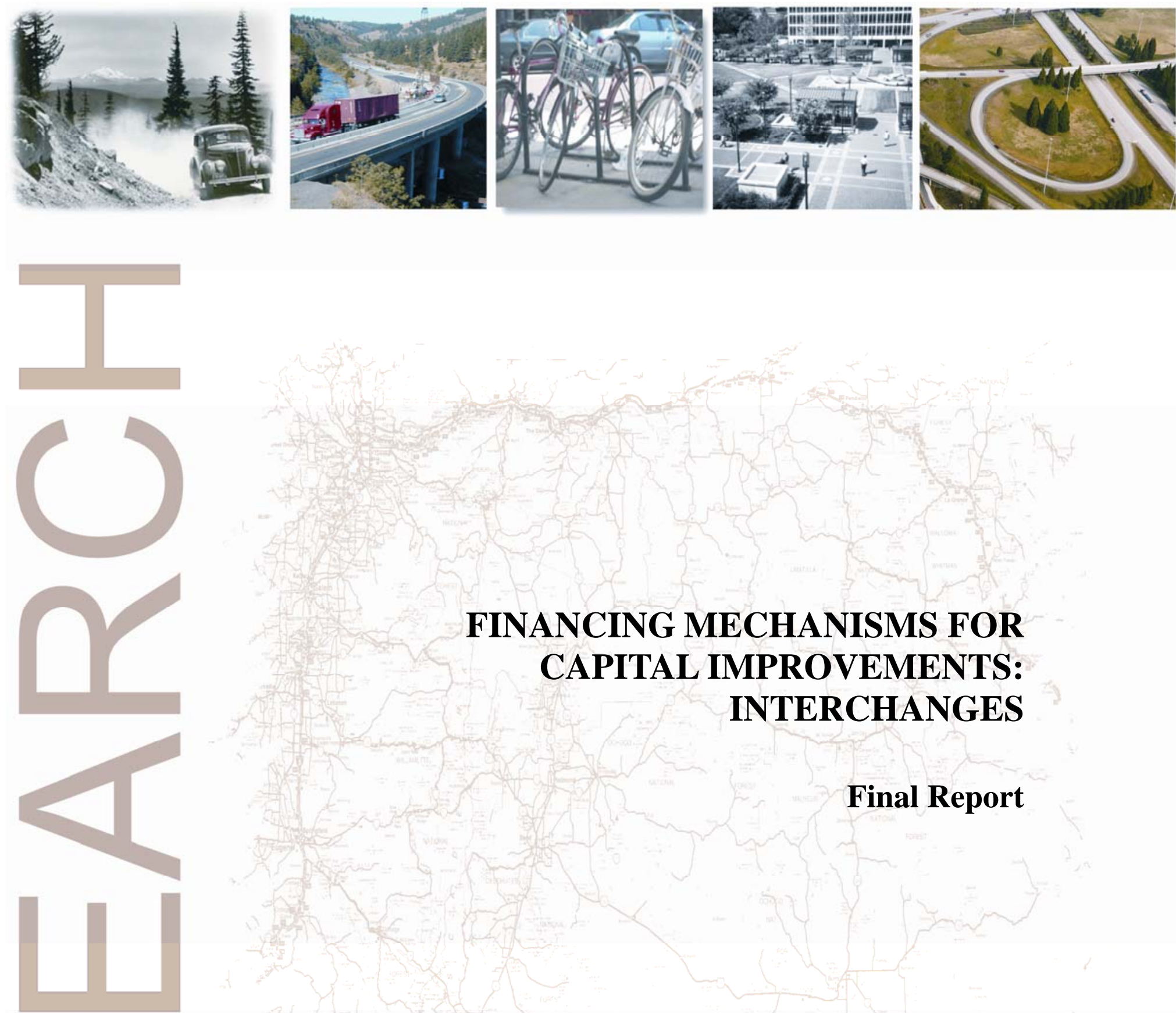

\title{
FINANCING MECHANISMS FOR CAPITAL IMPROVEMENTS: INTERCHANGES
}

\author{
Final Report
}
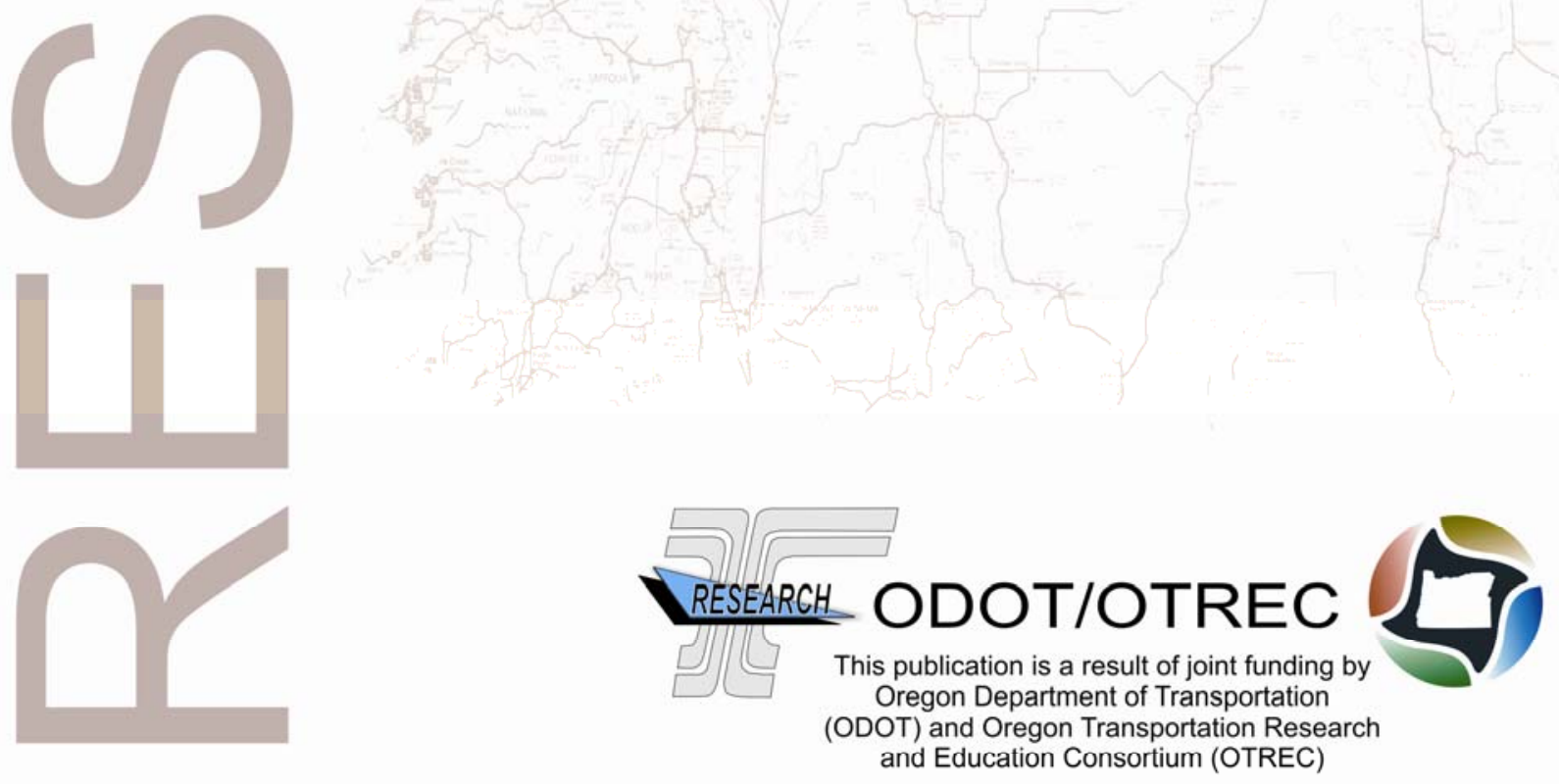



\title{
FINANCING MECHANISMS FOR CAPITAL IMPROVEMENTS: INTERCHANGES
}

\section{Final Report}

\author{
SPR 687 \\ OTREC-RR-10-07 \\ by \\ James G. Strathman \\ Elizabeth Simmons \\ Center for Urban Studies \\ Portland State University \\ P.O. Box 751 \\ Portland, OR 97207 \\ for \\ Oregon Department of Transportation \\ Research Section \\ 200 Hawthorne Ave. SE, Suite B-240 \\ Salem OR 97301-5192 \\ and \\ Federal Highway Administration \\ 400 Seventh Street, SW \\ Washington, DC 20590-0003
}

March 2010 

Technical Report Documentation Page
1. Report No.
2. Government Accession No.
3. Recipient's Catalog No.
FHWA-OR-RD-10-14
4. Title and Subtitle
Financing Mechanisms for Capital Improvements: Interchanges
5. Report Date
March 2010

6. Performing Organization Code

7. Author(s)

8. Performing Organization Report No.

James G. Strathman and Elizabeth Simmons

Center for Urban Studies

Portland State University

P.O. Box 751

Portland, OR 97207

9. Performing Organization Name and Address

10. Work Unit No. (TRAIS)

Oregon Department of Transportation

Research Section

200 Hawthorne Ave. SE, Suite B-240

Salem, OR 97301-5192

11. Contract or Grant No.

SPR 687

OTREC-RR-10-07

12. Sponsoring Agency Name and Address

Oregon Department of Transportation

Research Section

200 Hawthorne Ave. SE, Suite B-240

Salem, OR 97301-5192

Federal Highway Administration 400 Seventh Street, SW

Washington, DC 20590-0003
13. Type of Report and Period Covered

Final Report

14. Sponsoring Agency Code

15. Supplementary Notes

16. Abstract

This report examines the use of alternative local financing mechanisms for interchange and interchange area infrastructure improvements. The financing mechanisms covered include transportation impact fees, tax increment financing, value capture financing, local improvement districts, transportation corporations, state infrastructure banks, local option transportation taxes, fair share mitigation, and transportation concurrency. The financing alternatives are assessed in the context of Interchange Area Management Plans, which are required by the Oregon Transportation Commission, as well as in the context of the Oregon Department of Transportation's responsibilities under the state's Transportation Planning Rule.

17. Key Words

LOCAL FINANCING; FINANCING MECHANISMS; ALTERNATIVE FUNDING
18. Distribution Statement

Copies available from NTIS, and online at http://www.oregon.gov/ODOT/TD/TP_RES/
19. Security Classification (of this report) Unclassified

\author{
20. Security Classification (of this page) \\ Unclassified
}

21. No. of Pages

81 


\begin{tabular}{|c|c|c|c|c|c|c|c|c|c|}
\hline \multicolumn{10}{|c|}{ SI* (MODERN METRIC) CONVERSION FACTORS } \\
\hline \multicolumn{5}{|c|}{ APPROXIMATE CONVERSIONS TO SI UNITS } & \multicolumn{5}{|c|}{ APPROXIMATE CONVERSIONS FROM SI UNITS } \\
\hline Symbol & When You Know & Multiply By & To Find & Symbol & Symbol & When You Know & Multiply B & To Find & Symbol \\
\hline \multicolumn{5}{|c|}{ LENGTH } & \multicolumn{5}{|c|}{ LENGTH } \\
\hline in & inches & 25.4 & millimeters & $\mathrm{mm}$ & $\mathrm{mm}$ & millimeters & 0.039 & inches & in \\
\hline $\mathrm{ft}$ & feet & 0.305 & meters & $\mathrm{m}$ & $\mathrm{m}$ & meters & 3.28 & feet & $\mathrm{ft}$ \\
\hline yd & yards & 0.914 & meters & $\mathrm{m}$ & $\mathrm{m}$ & meters & 1.09 & yards & yd \\
\hline $\mathrm{mi}$ & miles & 1.61 & kilometers & $\mathrm{km}$ & $\mathrm{km}$ & kilometers & 0.621 & miles & $\mathrm{mi}$ \\
\hline \multicolumn{5}{|c|}{$\underline{\text { AREA }}$} & \multicolumn{5}{|c|}{ AREA } \\
\hline in $^{2}$ & square inches & 645.2 & millimeters squared & $\mathrm{mm}^{2}$ & $\mathrm{~mm}^{2}$ & millimeters squared & 0.0016 & square inches & in $^{2}$ \\
\hline $\mathrm{ft}^{2}$ & square feet & 0.093 & meters squared & $\mathrm{m}^{2}$ & $\mathrm{~m}^{2}$ & meters squared & 10.764 & square feet & $\mathrm{ft}^{2}$ \\
\hline $\mathrm{yd}^{2}$ & square yards & 0.836 & meters squared & $\mathrm{m}^{2}$ & $\mathrm{~m}^{2}$ & meters squared & 1.196 & square yards & $\mathrm{yd}^{2}$ \\
\hline ac & acres & 0.405 & hectares & ha & ha & hectares & 2.47 & acres & ac \\
\hline $\mathrm{mi}^{2}$ & square miles & 2.59 & kilometers squared & $\mathrm{km}^{2}$ & $\mathrm{~km}^{2}$ & kilometers squared & 0.386 & square miles & $\mathrm{mi}^{2}$ \\
\hline \multicolumn{5}{|c|}{ VOLUME } & \multicolumn{5}{|c|}{ VOLUME } \\
\hline $\mathrm{fl} \mathrm{oz}$ & fluid ounces & 29.57 & milliliters & $\mathrm{ml}$ & $\mathrm{ml}$ & milliliters & 0.034 & fluid ounces & $\mathrm{fl} \mathrm{oz}$ \\
\hline gal & gallons & 3.785 & liters & $\mathrm{L}$ & $\mathrm{L}$ & liters & 0.264 & gallons & gal \\
\hline $\mathrm{ft}^{3}$ & cubic feet & 0.028 & meters cubed & $\mathrm{m}^{3}$ & $\mathrm{~m}^{3}$ & meters cubed & 35.315 & cubic feet & $\mathrm{ft}^{3}$ \\
\hline $\mathrm{yd}^{3}$ & cubic yards & 0.765 & meters cubed & $\mathrm{m}^{3}$ & $\mathrm{~m}^{3}$ & meters cubed & 1.308 & cubic yards & $\mathrm{yd}^{3}$ \\
\hline \multicolumn{10}{|c|}{ NOTE: Volumes greater than $1000 \mathrm{~L}$ shall be shown in $\mathrm{m}^{3}$. } \\
\hline \multicolumn{5}{|c|}{$\underline{\text { MASS }}$} & \multicolumn{5}{|c|}{ MASS } \\
\hline $\mathrm{oz}$ & ounces & 28.35 & grams & g & g & grams & 0.035 & ounces & $\mathrm{oz}$ \\
\hline $\mathrm{lb}$ & pounds & 0.454 & kilograms & $\mathrm{kg}$ & $\mathrm{kg}$ & kilograms & 2.205 & pounds & $\mathrm{lb}$ \\
\hline $\mathrm{T}$ & short tons (2000 lb) & 0.907 & megagrams & $\mathrm{Mg}$ & $\mathrm{Mg}$ & megagrams & 1.102 & short tons $(2000 \mathrm{lb})$ & $\mathrm{T}$ \\
\hline \multicolumn{5}{|c|}{ TEMPERATURE (exact) } & \multicolumn{5}{|c|}{ TEMPERATURE (exact) } \\
\hline${ }^{\circ} \mathrm{F}$ & Fahrenheit & $(\mathrm{F}-32) / 1.8$ & Celsius & ${ }^{\circ} \mathrm{C}$ & ${ }^{\circ} \mathrm{C}$ & Celsius & $1.8 \mathrm{C}+32$ & Fahrenheit & ${ }^{\circ} \mathrm{F}$ \\
\hline
\end{tabular}




\section{ACKNOWLEDGEMENTS}

The authors gratefully acknowledge the efforts of Amanda Pietz, ODOT Research Section, for her effective management of this project. Appreciation is also expressed to the members of the project's Technical Advisory Committee (TAC), including: Nancy Murphy and Dick Reynolds, ODOT Planning and Implementation; Michael Ray, ODOT Region 1 Planning; Tracy White, ODOT Access Management; Denise Whitney; ODOT Long Range Planning; and Satvinder Sandhu, FHWA. Lastly, Terry Cole, ODOT Region 2 Planning, served as a friend of the TAC, providing insights on the evolution of ODOT's collaborative approach to interchange area planning, as well as focused comments on the preparation of the Woodburn Interchange Area Management Plan.

This project was jointly funded by the Oregon Transportation Research and Education Consortium (OTREC) and the Oregon Department of Transportation (ODOT).

\section{DISCLAIMER}

This document is disseminated under the sponsorship of the Oregon Department of Transportation, the United States (U.S.) Department of Transportation, and the U.S. Department of Transportation University Transportation Centers Program in the interest of information exchange. The State of Oregon and the U.S. Government assume no liability of its contents or use thereof.

The contents of this report reflect the view of the authors who are solely responsible for the facts and accuracy of the material presented. The contents do not necessarily reflect the official views of the Oregon Department of Transportation, U.S. Department of Transportation, or the U.S. Department of Transportation University Transportation Centers Program.

The State of Oregon and the U.S. Government do not endorse products of manufacturers. Trademarks or manufacturers' names appear herein only because they are considered essential to the object of this document.

This report does not constitute a standard, specification, or regulation. 
FINANCING MECHANISMS FOR CAPITAL IMPROVEMENTS: INTERCHANGES

TABLE OF CONTENTS

1.0 INTRODUCTION......................................................................................................

1.1 PURPOSE AND ORGANIZATION OF THE REPORT ............................................

2.0 ODOT POLICIES AND PRACTICES RELATED TO INTERCHANGE

AREA MANAGEMENT ........................................................................................................5

2.1 OREGON TRANSPORTATION PLAN AND OREGON HIGHWAY PLAN …….........5

2.2 ACCESS MANAGEMENT ........................................................................................6

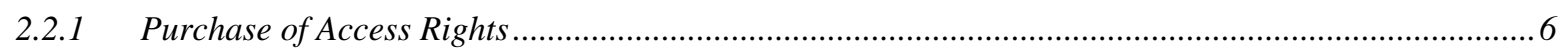

2.3 THE TRANSPORTATION PLANNING RULE.....................................................

2.4 NEGOTIATED MITIGATION AGREEMENTS ............................................................

2.5 INTERCHANGE AREA MANAGEMENT PLANS ......................................................

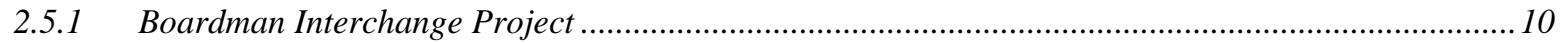

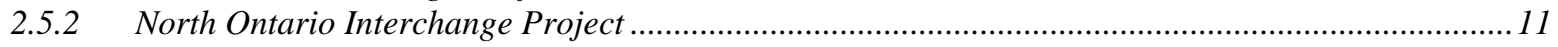

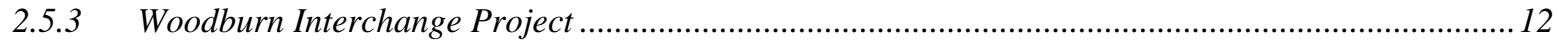

3.0 FINANCING MECHANISMS LITERATURE REVIEW ..........................................15

3.1 TRAFFIC IMPACT FEES (TIFS) / SYSTEM DEVELOPMENT CHARGES

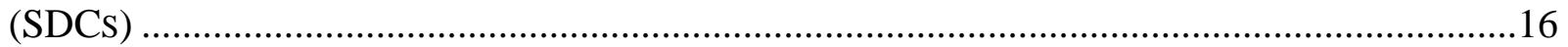

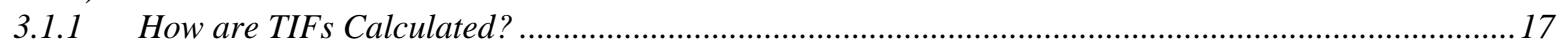

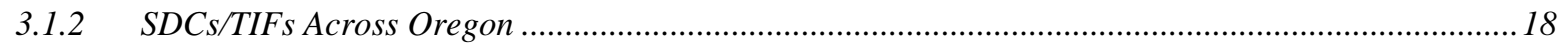

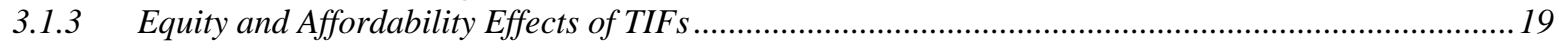

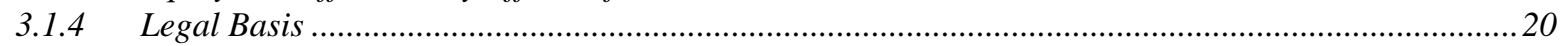

3.2 TRANSPORTATION UTILITY/MAINTENANCE FEES ............................................21

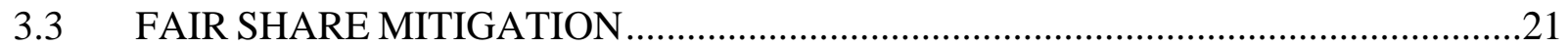

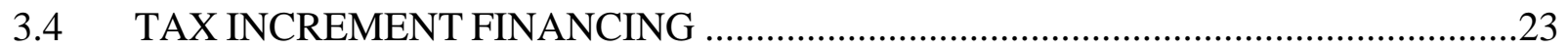

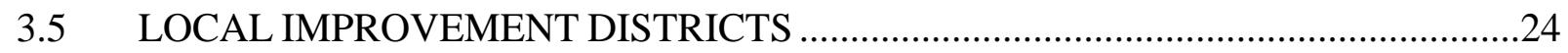

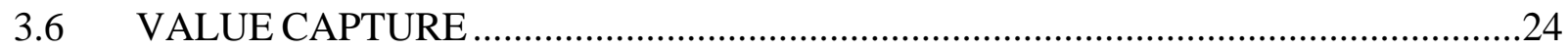

3.7 TRANSPORTATION IMPROVEMENT DISTRICTS ................................................26

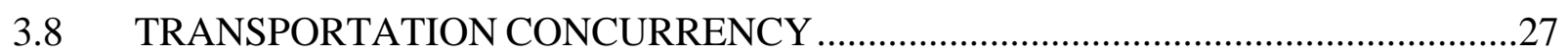

3.9 TRANSPORTATION CORPORATIONS ………..............................................2

3.10 LOCAL OPTION TRANSPORTATION TAXES.........................................................28

3.11 STATE TRANSPORTATION INFRASTRUCTURE BANKS .....................................29

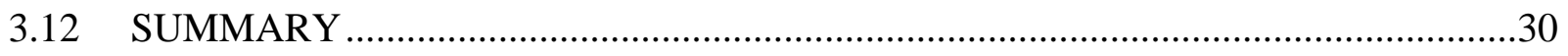

4.0 EVALUATION OF FINANCING MECHANISMS .......................................................35

4.1 YIELD/REVENUE POTENTIAL ...........................................................................36

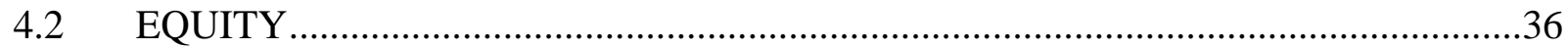

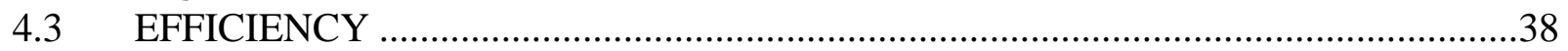

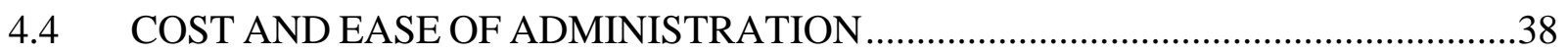

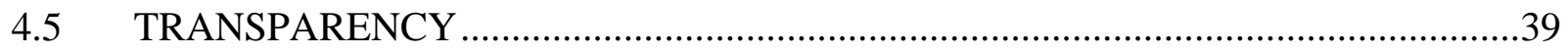

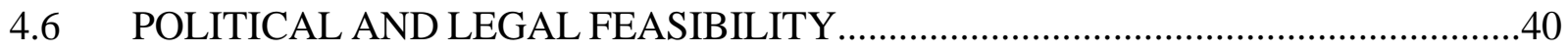




\subsection{FINANCING MECHANISMS EVALUATED AGAINST PUBLIC FINANCE}

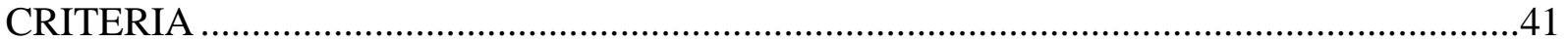

4.7.1 Traffic Impact Fees/System Development Charges ..........................................................................4

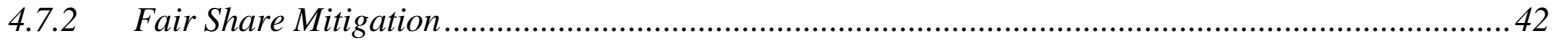

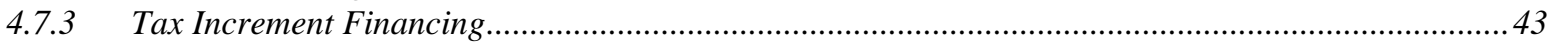

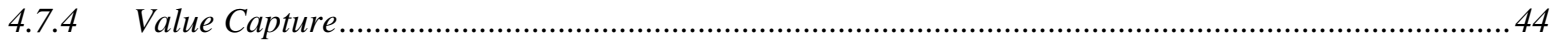

4.7.5 Local Improvement Districts/Transportation Improvement Districts ................................................ 45

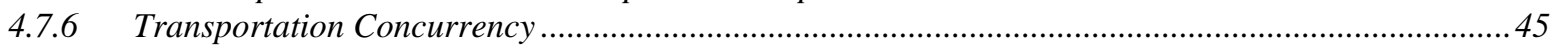

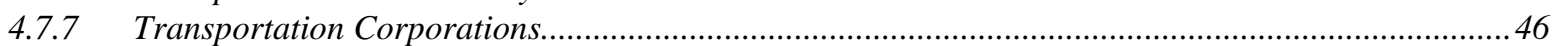

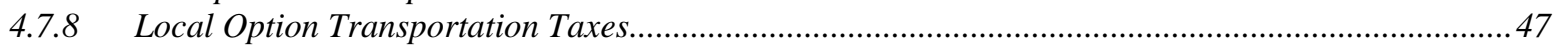

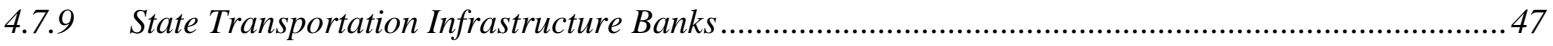

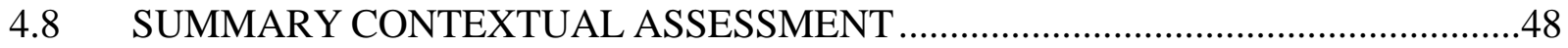

5.0 CASE STUDIES...............................................................................................................53

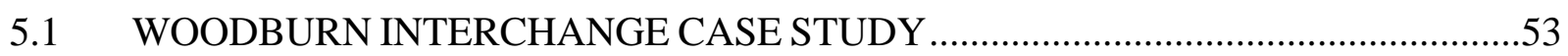

5.2 FERN VALLEY INTERCHANGE CASE STUDY ……………………………........57

6.0 CONCLUSION .................................................................................................................61

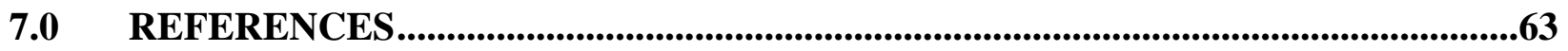

\section{LIST OF FIGURES}

Figure 5.1: Woodburn Interchange: Significant Planning, Funding, and Development Milestones............................54

\section{LIST OF TABLES}

Table 3.1: Summary Features of Alternative Financing Mechanisms....................................................................31

Table 4.1: General Contextual Suitability of Alternative Financing Mechanisms ........................................................50 


\section{EXECUTIVE SUMMARY}

This report examines the use of alternative local financing mechanisms for interchange and interchange area infrastructure improvements. The financing mechanisms covered include transportation impact fees, tax increment financing, value capture financing, local improvement districts, transportation corporations, state infrastructure banks, local option transportation taxes, fair share mitigation, and transportation concurrency.

The focus of the report on interchange applications reflects the policy and planning attention that have been directed toward these facilities, resulting in growing collaboration between ODOT and local governments. For example, Interchange Area Management Plans must be completed and approved by local governments and the Oregon Transportation Commission prior to construction or reconstruction of interchanges. These plans must identify state and local transportation system improvements necessary to ensure that interchange facilities perform as designed over their design life.

Secondly, the Transportation Planning Rule defines ODOT's responsibility to review proposed urban growth boundary and comprehensive plan amendments in the vicinity of interchanges. When such land use changes would result in a significant increase in interchange traffic volume, the Transportation Planning Rule requires local governments to identify improvements with committed funding to mitigate effects on interchange performance.

Lastly, common to both Interchange Area Management Plans and Transportation Planning Rule review, the Oregon Highway Plan designates mobility standards for all state facilities, including interchanges. These standards establish the basis for which facility and system plans are prepared, and against which land use changes are evaluated.

Financing mechanisms are first reviewed with respect to their general application to funding transportation improvements. This review provides a literature-based appraisal of their advantages and disadvantages, and, where applicable, examples of their use in Oregon. Subsequently, the focus is narrowed to assessing the financing mechanisms' suitability for funding interchange-related improvements. This assessment is based on established public finance criteria, including revenue yield and stability, efficiency and equity, cost and ease of administration, transparency, and political and legal feasibility. The assessment is also structured to account for differences in locational and land use contexts that research and past planning experience indicate are relevant to financing decisions on interchange improvements.

The report concludes with a presentation of two case studies that illustrate the approaches taken by ODOT and local governments in planning for and financing interchange improvements. Both case studies cover the preparation and content of Interchange Area Management Plans. However, the planning and development contexts involved in these efforts are substantively different. 
The principal conclusion of this report is that choices of financing mechanisms need to be sensitive to location and development context-specific conditions. Thus, while some alternatives exhibit characteristics that generally favor their use in given circumstances, none of the financing mechanisms predominates over the others, even considering the relatively narrow focus of the report on interchange area applications. Also, as one of the case studies shows, conditions may lead to the use of multiple mechanisms. In this respect, the report is intended to serve as a handbook for planners and decision makers, explaining how financing mechanisms work, describing how they have been applied, and presenting issues to be considered in making financing decisions. 


\subsection{INTRODUCTION}

The Oregon Department of Transportation (ODOT) uses various planning tools to protect the function and maintain the safety and operations of state facilities. These tools are contained in the agency’s Access Management Program, its review of local government Transportation System Plans (TSPs), its responsibilities under the Transportation Planning Rule (TPR), Development Review of local development applications, and preparation of Interchange Area Management Plans (IAMPs). Collectively, these tools provide a framework for ODOT to work with local governments when their actions potentially affect the performance of state facilities.

Over time, development pressures near state facilities result in a need to increase capacity or provide other improvements that protect the function of a facility, such as a grade separated interchange, and a need to finance these improvements. Comprehensive plan amendments and zoning changes affect capital planning that addresses future transportation needs, since they often result in the generation of additional trips that may exceed the capacity of the future planned transportation system, or otherwise compromise safety or operations.

In the future, as development pressures near state facilities increase, ODOT and local governments will need to consider ways to fund needed infrastructure improvements and expansion. This report thus explores financing mechanisms for capital improvements, focusing on the potential for coordination with Interchange Area Management Plans (IAMPs). The intent of IAMPs is to maintain the operation and safety of the interchanges and ensure compatibility with land use plans and the capacity and function of state and local transportation facilities. IAMPs are sometimes amended to address development beyond what existing plans recognize.

For existing interchanges without IAMPs, continued development under current zoning can eventually exhaust available capacity or compromise the safety and function of the facility. ODOT has no means of regulating or managing such development. In such cases where subsequent needs for interchange capital improvements arise, financing responsibility can have several dimensions; first, the determination of responsibility between ODOT and local governments (and by extension, private parties proposing development) and, second, between existing and future development.

ODOT's Planning Section has done a considerable amount of work on developing basic protocols for staff to use in negotiating fair, legally defensible and enforceable mitigation agreements with local governments and/or private developers in the development review process. "Chapter 5: Negotiated Mitigation Agreements” in ODOT’s Development Review Guidelines (2008) supports staff understanding of the opportunities and limitations that apply when negotiating such agreements, and to understand the legal framework within which ODOT may negotiate agreements for mitigation by developers and in cooperation with local governments. While this work lays out the existing framework under which mitigation agreements may be pursued, its treatment of local mechanisms for financing capital improvements is largely limited to voluntary contributions or contributions required to mitigate conditions related to issuing a Highway Approach Permit. Thus 
this report explores the financing tools that local governments could apply to state transportation facility improvements.

In the future, development pressures around many interchanges will result in the need to plan and finance improvements to maintain their function and safe operation. Where existing and planned facilities are not adequate to serve anticipated development, financing mechanisms that include local sharing of cost responsibility for development-related capital improvements will be needed. To date, there has been limited experience with local funding of state transportation facility improvements related to traffic impacts of local land use development.

\subsection{PURPOSE AND ORGANIZATION OF THE REPORT}

Oregon's experience with integrated land use and transportation planning now spans over 30 years. Although today's planning policies and systems still bear a strong resemblance to those established in the 1970s, more than three decades of development has had a substantial effect on planning programs and practices. Throughout the state's planning history, local governments have maintained responsibility for land use decisions, evidenced in local comprehensive plans that address zoning to guide land development and infrastructure improvements - including transportation.

Alternatively, ODOT is responsible for planning and maintaining the state transportation system. While it is not directly engaged in land use planning, ODOT has gradually become more involved when local planning and development affect state transportation facilities. ODOT's increasing involvement reflects a basic policy orientation change from an emphasis on adding capacity to better maintaining and preserving capacity already in place. While this change has a policy foundation in improving resource efficiency and ensuring environmental and climate protection, it also acknowledges a financial reality: the resources necessary to support ODOT's traditional role of adding capacity in direct response to development have not been available. Thus, in order to ensure that mobility is maintained on the state transportation system, ODOT is increasingly collaborating with local governments to manage development near state transportation facilities.

The financial challenges that Oregon's local governments face in developing and maintaining transportation infrastructure have also been substantial. Local government receipts of state gas tax revenues, along with dedicated revenues from development fees, have been increasingly falling short of what would be needed to sustain traditional infrastructure development and maintenance practices. Thus, both ODOT and local governments have been motivated to work together in managing development near state facilities, and in finding new ways to finance transportation infrastructure improvements occasioned by development.

Although collaboration with local governments arises wherever significant development occurs near state transportation facilities, the need for ODOT and local governments to work together is most clearly apparent in interchange areas. Interchange area locations, particularly in and near Oregon's urban centers, offer prime regional accessibility to large-scale commercial activities. Traffic volumes resulting from the development of such activities can substantially tax the capacity of interchanges and lead to their premature obsolescence. With a majority of the near-300 interchanges on the state highway system located in or near urban areas, the costs of improving 
facilities in place or adding new interchanges would be prohibitive were ODOT and local governments to take a passive approach to managing development and its traffic consequences. Alternatively, active collaboration in planning for mitigation of development impacts near interchanges ensures reasonable preservation of interchange capacity and more sustainable management of local transportation infrastructure.

Collaborative management of interchange area development does not eliminate the need to invest in transportation infrastructure, although it does seek to limit such costs and apportion them fairly among responsible parties. In this respect, local governments have increasingly turned to a variety of alternative financing mechanisms to fund local transportation infrastructure improvements in interchange areas and, in some instances, to contribute to the funding of interchange improvements. Documenting these financing mechanisms and assessing their applicability to interchange area transportation improvements are the main purpose of this report.

As should be subsequently evident, this report does not take a prescriptive approach in the sense of recommending specific infrastructure financing strategies. Any of the financing mechanisms covered in the report may provide a suitable means of funding transportation infrastructure, given prevailing local policy, planning and development circumstances. Thus, the report is intended to serve as a handbook, illustrating approaches that local governments in Oregon and elsewhere have employed in financing transportation infrastructure development.

The organization of the report is as follows. Section 2 provides a summary of the policies and programs that guide ODOT in managing the impacts of land development near state facilities and in coordinating with local governments to mitigate the functional and safety effects of development on interchanges.

Section 3 reviews the literature on the financing mechanisms employed by local governments to fund transportation improvements. The review includes general assessments from the literature of notable strengths and weaknesses of each of the financing mechanisms. Where applicable, examples of the use of each financing mechanism in Oregon are provided.

In Section 4, the general suitability of each financing mechanism is then assessed in relation to established public finance criteria. The chapter concludes with a contextual assessment based on a typology of interchange area development circumstances identified in prior research.

Section 5 provides two case studies of interchange area planning in Oregon illustrating the collaborative approach of ODOT and local governments, and the resulting local financing mechanisms contained in IAMPs.

Section 6 presents the conclusions of the report. 


\subsection{ODOT POLICIES AND PRACTICES RELATED TO INTERCHANGE AREA MANAGEMENT}

In this chapter, ODOT policies and practices that potentially relate to the financing of interchange area facility improvements are reviewed. These policies and practices are documented in the Oregon Transportation Plan (OTP), the Oregon Highway Plan (OHP), Access Management rules, guidelines for preparing Negotiated Mitigation Agreements, the Department of Land Conservation and Development's (DLCDs) Transportation Planning Rule, and Interchange Area Management Plan guidelines.

\subsection{OREGON TRANSPORTATION PLAN AND OREGON HIGHWAY PLAN}

The stated purpose of the OTP is "to promote a safe, convenient, efficient transportation system that promotes livability and economic success.” The OHP is part of the OTP. The OHP guides the management of the state highway system with the goals of increasing safety, preserving the system, and extending its capacity. Several policies in the OHP address ODOT's responsibility for interchange area management planning.

OHP Policy 1B, Land Use and Transportation, addresses “...the relationship between the highway and development on and off the highway system” (ODOT 1999). Policy 1B endorses compact development patterns because they lead to more efficient highway systems, stating that "ODOT and local and regional governments must work together to achieve accessibility and mobility goals for a balanced transportation system.” The policy clarifies how ODOT should work with local governments in order to connect land use and transportation goals. It emphasizes long-term goals and working with local governments on unique plans for each area that, together, support the maintenance of the highway system across the state. This includes ODOT's commitment to working with local governments to create smart local comprehensive plans and local transportation system plans that integrate land use and transportation planning, which contributes to the maintenance of the state highway system.

OHP Policy 1G, Major Improvements, outlines ODOT’s responsibilities for maintaining highway performance and safety by improving system efficiency and management before adding capacity. The main priority of this policy is to protect the existing highway system first, before making major improvements. The policy also specifies that ODOT will work with local governments in pursuing this goal.

OHP Policy 3C, Interchange Access Management Areas, explicitly addresses ODOT's role in interchange area management, stating that "it is the policy of the State of Oregon to plan for and manage grade-separated interchange areas to ensure safe and efficient operation between connecting roadways.” The main goal of OHP Policy $3 \mathrm{C}$ is to “...protect the function of 
interchanges to provide safe and efficient operations between connecting roadways and to minimize the need for major improvements of existing interchanges.” ODOT is required to develop IAMPs whenever an existing interchange is improved or a new interchange is planned. Action 3C.2 specifies that local transportation system improvements in the interchange management area are required to be "identified in the local comprehensive plan and committed with an identified funding source.” This policy also directs ODOT to purchase access control on crossroads around existing interchanges for a distance of 1,320 feet when possible.

\subsection{ACCESS MANAGEMENT}

ODOT manages access to the state highway system through Oregon Administrative Rule (OAR) Division 51: Highway Approaches, Access Control, Spacing Standards and Medians. OAR 734051-000, the Access Management Rule, addresses the "location, construction, maintenance and use of approaches onto the state highway rights-of-way and properties under the jurisdiction of ODOT." The rules outlined under OAR 734-051 "govern closure of existing approaches, spacing standards, medians, deviations, appeal processes, grants of access and indentures of access.” Division 51 establishes standards for interchange access spacing as part of an IAMP, and provides for the development of access management plans (AMPs) along state highways.

Policy Goal 3 in the OHP addresses the intentions of access management as follows: "to employ access management strategies to ensure safe and efficient highways consistent with their determined function, ensure the statewide movement of goods and services, enhance community livability and support planned development patterns, while recognizing the needs of motor vehicles, transit, pedestrians and bicyclists.”

Access management is defined in the transportation literature as "a structured mechanism for controlling access to transportation facilities in order to achieve defined goals and objectives relating to the facilities” (Freilich and White, 1994: p. 1). Access management again emphasizes the need for better coordination between transportation and land use planning. OAR 734-051-0155, Access Management Plans and Interchange Area Management Plans, specifies ODOT's role in the development of plans to "maintain and improve highway performance and safety by improving system efficiency and management before adding capacity.”

OAR 734-051-0155 also stipulates that Access Management and Interchange Area Management Plans "must be consistent with the Oregon Highway Plan, must be used to evaluate development proposals and may be used to determine mitigation for development proposals.”

\subsubsection{Purchase of Access Rights}

ODOT has the ability to purchase access control and access rights on local roadways if it can demonstrate that established access is associated with negative impacts on state highway facilities. The purchase of access rights allows ODOT to limit or amend a property's established access to state highway facilities. More generally, the right of access is considered to be subordinated to the regulations necessary to ensure public safety (see Paradyne Corp. v. Florida DOT, 1988). However, the purchase of access must be done under reasonable conditions. The cost and complications of purchase of access rights can be avoided when comprehensive planning is used to 
address these types of issues before they become a problem. About three-fourths of the state DOTs surveyed by Butorac and Wen (2004) purchased access rights in the vicinity of new or improved interchanges to ensure lasting operational and safety benefits.

\subsection{THE TRANSPORTATION PLANNING RULE}

Most cities and counties in Oregon, unless they are very small communities, are required to prepare Transportation System Plans, which must be compatible with the OHP according to the Transportation Planning Rule (TPR). Established in the early 1990s, Oregon's TPR (OAR 660-012) was adopted to "implement Statewide Planning Goal 12 (Transportation) and to promote the development of safe, convenient and economic transportation systems that are designed to reduce reliance on the automobile so that the air pollution, traffic and other livability problems faced by urban areas in other parts of the country might be avoided.” Goal 12 emphasizes the relationship between transportation and land use and "requires that plans for new facilities or expansion of existing facilities, must identify the impact on local land use patterns and existing transportation systems.”

The TPR gives ODOT the authority to influence land use decisions that will impact state transportation facilities and the ability to negotiate with local governments. Section 660-012-0045 of the TPR requires cities to influence and apply conditions to development proposals in order to minimize impacts to transportation infrastructure and facilities.

The TPR was challenged in the Jaqua v. City of Springfield land use appeal in 2004. Robin and John Jaqua, property owners and residents of Springfield, challenged the City's rezoning of a medium-density residential area in order to allow construction of a hospital. The court found in favor of Jaqua, concluding that it was insufficient to make a decision based only on the last year of a 20-year planning period and that intervening years should also be considered. McCourt (2006, $p$. 57) points out that the Jaqua decision “was viewed as a 'concurrency' requirement by the TPR, and 'repairs' made were to establish the plan horizon year as the basis for the determination of transportation facility impacts of comprehensive plan amendments. The changes to the rule also directed that transportation system improvements that could be relied upon to mitigate development impacts related to plan amendments must have funding identified in adopted transportation plans or otherwise be found to be 'reasonably likely' to be built by the subject system owner (ODOT or a local road authority) within the plan period.

Following the Jaqua decision, the TPR was amended in 2005 to clarify the transportation findings required to justify rezoning. The TPR amendments redefined ODOT's role in mitigating traffic impacts of land use changes near interchanges, with the result that "any rezone action that is within a $1 / 2$ mile radius of the center of the interchange would now be required to assess the interstate interchange ramp capacity and access spacing needs” (McCourt 2006, 58). Previous research had shown that amendments to local comprehensive plans generally had the effect of increasing traffic volumes at interchanges, particularly those located in rural and urban fringe areas (Strathman et al. 2005). The TPR amendments thus provided ODOT with a means of ensuring that local governments accounted for such traffic impacts in their land use and transportation plans. 
The TPR amendments defined a process for ensuring that zoning changes contained in comprehensive plan amendments, urban growth boundary expansions, and annexations can be supported by existing and planned transportation facilities in local TSPs. Changes were also made to provide more emphasis on transportation impacts of comprehensive plan amendments and zoning changes on the transportation system. If it is determined that the traffic increase associated with a zoning change has a significant effect on the performance of local or state facilities (as represented by level of service standards in TSPs and mobility standards contained in the OHP), the effect must be mitigated by either limiting land uses or by committing to capacity, operational and/or safety improvements. Any necessary local capacity improvements must be identified in TSPs - with committed funding. For affected state facilities, the improvements must be identified in the State Transportation Improvement Program (STIP). In the absence of committed funding, the affected jurisdiction can still satisfy the TPR requirement by making a claim that it is "reasonably likely" that the necessary funding would be committed by the end of the planning period (usually 10-20 years out for local jurisdictions, and 15 years at a minimum for ODOT).

Cortright (2008) reported that there were 120 comprehensive plan amendments involving findings of significant traffic impacts in the two-year period following the TPR amendment, and most involved a zoning change to commercial land use along state highways. He observed that the lack of committed funds for capacity improvements, and few claims that funding would be "reasonably likely,” were contributing to a growing reliance on land use mitigation efforts (e.g., "trip caps”), increasing interest in "refining" OHP mobility standards, and a growing interest in identifying new ways of financing capacity improvements.

In response to the expanding incidence of land use changes with significant transportation impacts and limited local and state funding for transportation improvements, the Oregon Legislature passed HB 3379 during its 2009 session. The legislation provides a new set of options for satisfying the TPR amendment's conditions when land use changes result in significant transportation impacts and funding to mitigate these impacts is not reasonably likely to be available. The new options available to local governments are as follows:

1. Local governments can apply for a time extension to meet the TPR requirements.

2. Local governments can submit a plan to ODOT and the OTC proposing alternative funding mechanisms for financing improvements to meet the mobility standards in the OHP.

3. Local governments can apply to ODOT to either a) adjust the pertinent mobility standard for a period not to exceed 20 years, or b) to allow alternative transportation performance measures other that volume to capacity ratios (v/c) currently used as the state system mobility standard.

\subsection{NEGOTIATED MITIGATION AGREEMENTS}

Negotiated mitigation agreements are voluntary compacts between ODOT and local governments or private developers. They represent another aspect of ODOT's involvement in interchange area management. ODOT coordinates such agreements to ensure that state transportation facilities are not adversely affected by land development. This requires working with local governments and 
private developers to identify changes in proposed developments that need to be made in order to maintain highways and other state transportation infrastructure.

There are two broad categories of mitigation measures that involve developer contributions: “1) a proportional share contribution to an ODOT STIP project or 2) developer construction of or payment for an improvement that compensates for the impacts of the private development on the highway facility” (ODOT 2008).

Negotiated mitigation agreements are implemented through permits, letters of agreement, memorandums of understanding (MOUs), intergovernmental agreements (IGAs), and cooperative improvement agreements (CIAs). IGAs and CIAs are binding agreements, while the other types of agreements usually are not. CIAs are the strongest type of agreement for ensuring that developers follow through with improvements, and involve an agreement between ODOT and a local government or ODOT and a developer. CIAs require that either the local government or the developer agree to make improvements to the state transportation facility and roles and responsibilities are assigned.

When mitigation measures occur as exactions, or formal conditions of development approval, they must be directly related to the impacts of development (see Nollan v. California Coastal Commission, 483). Rough proportionality between the impact and the mitigation measure is another requirement of the legal enforceability of an exaction (see Dolan v. City of Tigard). Together, these considerations constitute what is known as the "rational nexus" test that must be satisfied in mitigating development impacts. Given that negotiated mitigation agreements are voluntary exercises, they have not been legally subjected to the rational nexus test applied to exactions.

\subsection{INTERCHANGE AREA MANAGEMENT PLANS}

ODOT is most directly involved in interchange area management through the practice of preparing IAMPs, which are required for all new interchanges and should be developed for significant modifications to existing interchanges. An IAMP is “... a joint ODOT and local government longterm (20+ years) transportation and land use plan to balance and manage transportation and land use decisions in interchange areas" whose intent is to "... protect the function of the interchange, the state highway and the local street network” (ODOT 2006, p.2). ODOT initiates the preparation of an IAMP under the following conditions:

- for the construction of a new interchange;

- for significant modifications of an existing interchange;

- at the directive of the Oregon Transportation Commission; or

- at the directive of an ODOT Region office.

ODOT works collaboratively with a local government in preparing an IAMP. An IAMP provides coordinated land-use and transportation plans that ensure the availability of adequate transportation infrastructure. ODOT participates in IAMPs by: 
- determining that an IAMP is needed;

- identifying future facility function and needs;

- developing objectives to be adopted by local and state government;

- providing technical assistance; and

- identifying funding sources.

The Oregon Transportation Commission adopts finalized IAMPs as amendments to the OHP.

IAMPs are different from traditional access management plans in that they address the issue of traffic in the surrounding area, as well as address traffic increases from land development. Access management plans are typically included as elements of IAMPs, but they are also developed as stand alone plans where an interchange improvement is not involved. Local TSP provisions that apply to the IAMP study area are included in plan documents to provide context for the plan.. The IAMP planning process often involves amendment of a TSP, identifying policy changes and improvements to local facilities that are needed to support the function of the interchange and/or proposed interchange improvements.

The financing mechanisms considered in this report provide a potential means of funding transportation facility improvements identified in an IAMP. Thus, a summary description of selected IAMPs is provided below to illustrate the role of funding in the IAMP process.

\subsubsection{Boardman Interchange Project}

In 2007, the City of Boardman completed preparation of an IAMP for two interchanges that connect the city to I-84 -- the Main Street Interchange (Exit 164) and the Laurel Lane Interchange (Exit 165, also referred to as the Port of Morrow Interchange). The IAMP was completed to ensure that in the future these interchanges would continue to be safe and allow for efficient operation, both locally and regionally. The area covered by the IAMP included the entire city of Boardman and the Port of Morrow. Future development in this area will be considered in relation to its potential impact on the functioning of the interchanges.

Traffic forecasts indicated that both interchanges will lack capacity by 2026 in the event that no improvements were made. A plan was prepared to improve local connectivity of existing and planned streets in the IAMP area, which would also result in improved flow at the interchanges. Implementation of an access management plan was also identified as a necessary step in achieving access goals. However, it was determined that achieving full compliance with Division 51 access standards would not be possible due to existing and predicted development.

The following policy was incorporated in the IAMP to ensure that goals to protect the interchanges are kept in mind as development occurs: "It is the policy of the City of Boardman to plan for land uses within the interchange areas consistent with the IAMP adopted by the city and ODOT. The city shall review proposed plan and land use regulation amendments within the Interchange Management Areas for consistency with the IAMP. Where a proposed plan or land use regulation amendment would result in a property generating more traffic than previously estimated in the 
IAMP, the city will coordinate with ODOT to amend the IAMP as necessary, to accommodate the proposed use prior to approval of the proposed amendment” (DKS Associates 2007, 13).

Funding has not yet been committed for interchange improvements. However, the City of Boardman is considering contributing local funds to improve the interchange (DKS Associates 2007, 77). Cost estimates for Main Street interchange improvements, such as "additional approach lane on exit ramp" at \$150,000 and "reconstruct overpass" at \$10-15 million, identify both ODOT and the City of Boardman as potential funding sources. Local funding sources under consideration include system development charges or creation of local improvement districts.

The City of Boardman has a system development charge (SDC) ordinance (Ord. 199-1999) specifying a methodology for determining SDCs. The ordinance states that funds raised from SDCs can only be spent on capacity-increasing capital improvements associated with systems for which the fees are assessed. The ordinance does not prohibit using funds raised from SDCs as contributions toward funding state facilities.

\subsubsection{North Ontario Interchange Project}

An IAMP was prepared in 2005 for the North Ontario project, which will result in construction of a new interchange and bridge at the intersection of OR 201 and I-84. Ontario had amended its urban growth boundary in 1999 and, as part of this change, 103 acres of land zoned for residential development in the IAMP study area was rezoned as commercial. This zoning change would have the potential to increase traffic volumes locally and on state facilities. The North Ontario IAMP was prepared in order to accommodate expected traffic growth while maintaining the safety and function of the interchange.

An access management plan was also completed as part of the IAMP, which identified property and access points in the interchange area likely to be affected by future growth. The access management plan will be applied in the future by ODOT, the City of Ontario, and Malheur County when making land use decisions in the IAMP area. The City of Ontario and Malheur County will include the North Ontario IAMP as amendments to their TSPs. ODOT requested that the city and county enter into a binding Cooperative Improvement Agreement for the interchange project.

Oregon Transportation Investment Act (OTIA) funding of the interchange was approved by the Oregon Transportation Commission (OTC). ODOT committed 100\% funding of the design and construction costs. Local funding was designated for local road improvements, and potential financing tools included local improvement districts and system development charges.

System development charges have only recently been adopted in North Ontario, under a resolution passed by the City Council in July 2006 (Resolution \#2006-129, A Resolution Establishing Fees and Charges for System Development Fees for the City of Ontario). The resolution lays out a schedule for transportation SDCs based on the Institute for Transportation Engineers (ITE) Land Use Code per unit of development. It appears that the IAMP planning process motivated the City of Ontario pursuing the authority to collect system development charges. 


\subsubsection{Woodburn Interchange Project}

Woodburn's interchange is located at the intersection of I-5 and OR 214/219. The Woodburn IAMP was completed in 2006. In the IAMP the City of Woodburn agreed to contribute funding for interchange improvements by implementing an interchange development charge on new development within the interchange area. The City also agreed to contribute traffic impact fee funds collected citywide to the planned improvements. The project is still in development and construction will begin in 2013 at the earliest.

Replacing the existing diamond interchange with a new cloverleaf design will improve safety and traffic flow, and will allow the interchange to meet OHP mobility standards. The improvement will also create enough capacity to serve the growth assumptions outlined in the 2005 Woodburn Comprehensive Plan. The IAMP also establishes a "trip-budget" in the interchange management area (IMA) that will allow the city and state to preserve interchange capacity into the future. The trip budget was calculated to be great enough to accommodate peak period travel, but low enough to discourage excessive use of the interchange. Peak hour targets were set at 2,500 vehicles per hour until 2020 for commercial and industrial purposes, with an additional 1,500 peak hour residential trips. The IMA trip budget will be distributed to vacant commercial and industrial parcels in the area on a first-developed, first-served basis (ODOT 2006b: p. 87).

One of the goals of the Woodburn IAMP was "to provide an interchange funding strategy that enables ODOT to acknowledge the Woodburn Interchange reconstruction as a planned improvement in the Woodburn Comprehensive Plan and TSP” (ODOT 2006b, p. 14). ODOT's acknowledgment of the planned interchange reconstruction served to satisfy the "reasonably likely" provision of the 2005 TPR amendments. The IAMP set forth a funding strategy that reflected the expectation that the interchange improvements would benefit the City of Woodburn, and that they should thus be responsible for covering part of its costs.

Most of the \$50 million designated for the project will come from the STIP. The City of Woodburn agreed to provide \$2.5 million for early right-of-way (ROW) acquisition. The City of Woodburn and ODOT also signed an IGA, establishing that the City's cost share for reconstruction of the interchange will be \$8 million. Woodburn will pay for its share of the costs from SDC funds and from funds generated by a recently adopted Interchange Development Charge (IDC).

Section 2 of Woodburn's SDC ordinance (Ordinance No. 2438) authorizes IDCs to help pay for the Woodburn Interchange project, and outlines conditions under which these charges may be collected. According to the ordinance, all new development within the IDC boundary is required to pay an IDC at the time building permits are issued. Development in the interchange management overlay district is required to pay IDCs, in addition to the SDCs that all development in Woodburn is required to pay. The IDC ordinance was established under the authority of ORS 223.297223.314, which defines the framework for establishing system development charges by local governments. The ordinance states that development within the IDC boundary will both create a larger impact on the interchange and will receive greater benefits than development outside of the boundary. Thus, it was determined that imposing IDCs on development within the boundary was "fair and equitable." 
Several arguments were previously raised against the imposition of IDCs and were addressed in the ordinance, as follows:

H. An argument was raised before the City Council that the IDC is unlawful because it "represents the effective establishment of a transportation special district without undergoing the adoption methods required by ORS Chapter 267.510 et seq." The City Council finds that this argument is not well founded in law because the City is asserting no jurisdictional authority outside of its corporate boundary.

I. Pursuant to ORS Chapter 267.510 et seq, a transportation district, like other special districts, exercises jurisdictional authority within the area of its boundary. By establishing the IDC boundary, the City Council, consistent with ORS 223.297-223.314, is merely establishing a charge that is collectible within the City. A Transportation SDC must be paid only: (1) if the involved property is annexed to the City, and (2) if the involved property develops. This is legal and within the City's jurisdiction.

J. Another argument was raised before the City Council that the IDC charge is inequitable. As stated above, the City Council finds that this is not the case because developing properties within the IDC boundary will create a greater developmental impact and also will receive a greater benefit by an improved Woodburn Interchange.

K. Finally, an argument was raised before the City Council that the IDC charge violates constitutional principles. The City Council finds that this argument is also not well founded in law. In Roger's Machinery v. Washington County, 181 Or.App 369,45 P.3d 966 (2002), the Court addressed the argument that traffic impact fees imposed under ORS 223.297223.314 constituted an unconstitutional taking in violation of the Fifth Amendment. The Court ruled that the traffic impact fees were not physical exactions and were not subject to Dolan's heightened scrutiny test, which is used to determine whether a property development condition constitutes an improper taking under the Fifth Amendment. The Court stated that no individualized determination was required before assessing the fee against a particular property in compliance with the Oregon SDC statutes.

The argument that the IDC is inequitable was raised by at least one developer on the grounds that existing development should also be required to contribute to the cost of the interchange improvements. At a city council meeting, some business people argued that SDCs were driving away developers. The City countered this claim, pointing out that the Woodburn has experienced unprecedented building in the last 10 years, despite the existence of SDCs during that time.

The methodology for determining the IDC is presented in the report "Transportation System Development Charge Study” of March 2008. 


\subsection{FINANCING MECHANISMS LITERATURE REVIEW}

Across the country, state transportation departments and local governments face challenges in financing infrastructure improvements, as traditional revenue sources have failed to keep pace with capital needs. Federal contributions to states have decreased, citizens have resisted tax increases for decades, and vehicle fuel efficiency improvements have eroded the yield of gas taxes (Puentes and Prince 2003; Sjoquist 2003; TRB 2006; Wachs 2003). In Oregon, the gas tax provides the largest source of revenue for funding maintenance and capital expenditures on the state highway system, but it is increasingly falling short of the state's needs. Prior to the 2009 legislative session, Oregon's gas tax had not been raised since 1993. In states with higher rates of development and traffic growth, the problem of funding transportation infrastructure capital and maintenance has become particularly acute.

Resistance to state gas tax increases also affects local governments, who depend on disbursements of state gas tax revenue to support local transportation programs. The ability of local governments to support transportation and other public services from their general fund revenues has also been hampered since the 1970s by voter-approved property tax limitation measures. With traditional sources of transportation funding increasingly falling short of funding needs, local governments have turned to alternative means of raising revenue to fund transportation services (AECOM Consult 2007; Bowles and Nelson 2008).

The need to supplement traditional transportation revenue streams is especially important in states with rapidly developing urban areas, in which infrastructure quickly becomes overwhelmed without proper planning and adequate investment. One strategy that is being increasingly pursued by local governments is to use alternative financing mechanisms that require the private sector to contribute to public infrastructure maintenance and improvements. Public-private partnerships between local governments and private developers are a growing source of revenue, relieving local jurisdictions of some of their infrastructure cost burdens.

The movement of state and local transportation finance away from gas taxes has both efficiency and equity implications. Regarding efficiency, one advantage of the gas tax is its general (although gradually weakening) correspondence to motorists' use of the transportation system. Oregon's transportation finance system has been viewed as more efficient than other states because of its greater reliance on taxes that vary with system usage and impact (i.e., from gas and weight-mile taxes) rather than fixed charges which do not vary with use (i.e., from vehicle registration fees) (Winston 1991). Beyond these traditional taxes, there is an opportunity for improving efficiency by switching to a tax based on vehicle miles traveled (VMT) or a tax that addresses congestion, climate, and other externalities. At the local government level, the efficiency implications of increasing reliance on alternative financing mechanisms is more uncertain, although both Forkenbrock (2006) and Lee (1988) conclude that shifting taxes and charges away from transportation system users is likely to lead to efficiency losses. 
With respect to equity, the traditional transportation policy emphasis has been on maintaining a correspondence between benefits and ability to pay among system users, with particular attention given to variations in the incidence of costs and benefits across income levels, transportation modes, and locations. The movement toward new financing mechanisms at the federal, state, and local levels has added new equity issues that have not yet been thoroughly assessed (Rosenbloom 2009).

This chapter reviews alternative local financing mechanisms for transportation infrastructure improvements. Financing mechanisms are described, along with their potential advantages and drawbacks. When possible, examples of utilization in Oregon are given. Williams (2006) presents a comprehensive review of local financing mechanisms, providing case studies of transportation corporations, transportation improvement districts, tax increment financing, fair share mitigation, transportation impact fees and transportation concurrency.

\subsection{TRAFFIC IMPACT FEES (TIFS) / SYSTEM DEVELOPMENT CHARGES (SDCS)}

SDCs and TIFs provide a way to distribute the cost of development-related growth and wear on local infrastructure to those who have benefited from infrastructure services, rather than requiring the general public to pay for these costs. According to Nicholas and Nelson (1988), SDCs and TIFs are "a monetary charge imposed by a local government on new development to recoup or offset a proportionate share of public capital costs required to accommodate such development with necessary public facilities.”

The use of impact fees to pay for new infrastructure is growing in popularity in municipalities across the country, especially in high-growth areas. For example, $83 \%$ of all Florida cities and $90 \%$ of California's cities employ some form of impact fee (AECOM Consult 2007). The National Surface Transportation Infrastructure Financing Commission supports the use of impact fees to generate revenue for transportation infrastructure at the local level, stating "the Commission broadly supports strategies that impose targeted sales taxes, property taxes, developer assessments, and so forth on individuals and businesses that directly benefit from specific transportation investments” (2009, p.94).

When communities in Oregon decide to adopt SDCs, they are required to follow guidelines laid out in ORS 223.297-223.314. The intent of this statute is to "provide a uniform framework for the imposition of system development charges by local governments, to provide equitable funding for orderly growth and development in Oregon's communities and to establish that the charges may be used only for capital improvements." There is no one standardized methodology for calculating SDCs that local governments are required to use, but rather a set of guidelines to which they must adhere (223.304).

ORS 223.302 stipulates allowable use of SDC revenues. Administrative review procedures must be established that allow any interested person to challenge the expenditures of SDCs. SDCs "may not be expended for costs associated with the construction of administrative office facilities that are more than an incidental part of other capital improvements or for the expenses of the operation or maintenance of the facilities constructed with system development charge revenues” (ORS 
223.307). A distinction is made between the ways that reimbursement fees and improvement fees can be spent. Reimbursement fees can only be spent on capital improvements, whereas improvement fees can only be spent specifically on capacity-increasing capital improvements. Transportation SDCs are usually defined as improvement fees.

\subsubsection{How are TIFs Calculated?}

Research comparing the ways that local jurisdictions calculate TIFs indicates that there is wide variation in methodologies (Leithe and Montavon 1990; Draper 1987). Dueker et al. found that "much of the variation in the methods of calculating the fees reflect different methods of calculating traffic impact or trade-offs between accuracy and simplicity" (1993: p. 7).

The TIF rate is based on the cost of building the needed capacity that results from growth-related trips. The Institute of Transportation Engineers Trip Generation Manual is used as a guide by many local governments to determine trip generation. Land use categories have a number of trips attached to them and are then priced accordingly. The residential land use category is charged a certain amount per number of dwelling units, while the commercial category is charged based on the gross floor area or gross leaseable area. For schools, the TIF is determined by the number of students, for movie theaters the number of screens and for service stations the number of vehicle fueling positions.

Many TIFs are based on the following general formula:

Charge $=[$ TGR $*$ Size $*$ ATL/2] $*[$ Cost $/$ Capacity $]$,

where TGR is the vehicle trip generation rate per unit of development; Size is the number of units of development associated with the project; ATL is the average trip length for trips associated with this type of project; Cost is dollars per lane-mile needed to construct roads in the area; and Capacity is the number of vehicle miles per lane mile (Dueker et al. 1993).

Depending on the complexity of the formula used, the trip generation rate can be adjusted based on various factors such as average trip length; the percentage of trips that represent new trips, and peak versus off-peak trips (Dueker et al. 1993). A particularly important factor that is difficult to measure when determining which trips are made because of new development and which are not, is the "trip-chaining" factor. Trip-chaining refers to cases in which travelers make multiple stops in the course of a journey. Adding the variable "percentage of new trips" can help to eliminate uncertainty caused by trip chaining (Nicholas et al. 1991).

An alternative TIF formula that doesn't directly include road construction cost is as follows:

$\mathrm{TIF}=\mathrm{Fee} * \mathrm{TGR} * \mathrm{ADJ}$,

where TIF is the charge per unit of development; Fee is the amount charged per trip; TGR is the trip generation rate for a particular land use; and ADJ represents an adjustment factor accounting for such effects as trip length, percentage of trips occurring at peak hours, percentage of trips that are new to the road system, and trip generation by trucks (Dueker et al. 1993). 
TIF or SDC rate adjustments in exchange for developer contributions are not usually employed by local governments. In Portland, Oregon however, transit-oriented developments receive a discount, and all SDCs except wastewater and storm water drainage are waived for certain types of affordable housing projects (City of Portland, Office of Management and Finance 2002).

Generally, it has been concluded that traffic impact fees do not cover the full cost that development imposes on public infrastructure (Dueker et al. 1993). The cost of traffic impact fees, based on a national survey of 206 local governments, averaged $\$ 1,567$ for single homes per unit, $\$ 1,364$ for general industry per 1,000 square feet, $\$ 2,141$ for general office per 1,000 square feet and $\$ 3,268$ for general retail per 1,000 square feet (Callies and Richardson 2000). However, the range of fee amounts for each category was considerable. For example, TIFs for retail development ranged from a low of $\$ 200$ per 1,000 square feet to a high of $\$ 36,063$ per 1,000 square feet (ibid).

Although the method used to calculate TIFs may appear to be rigorous, the actual trip generation for a given development can sometimes differ substantially from the trip generation rate used to calculate the TIF. The trip generation rate for a given land use reported in the ITE Trip Generation Manual, for example, represent an estimate derived from national surveys covering a variety of circumstances. Information that might be used to refine published trip rates to better reflect local development and traffic conditions may not be readily available. Lastly, formulas designed to differentiate among various kinds of development can become very complicated, making the logic of a TIF less transparent (Dueker et al. 1993).

\subsubsection{SDCs/TIFs Across Oregon}

The City of Eugene Public Works Department completed a study in 2004 comparing SDCs across 18 cities in Oregon. Transportation SDC rates varied considerably, with a high of $\$ 734,842$ in Woodburn to a low of $\$ 45,272$ in Newberg, based on the rate for a 47,400 square foot supermarket. All of the cities surveyed indicated that they based their trip rates on the ITE Trip Generation Manual. Some cities based the rate on the ITE weekday average daily traffic, while others used the ITE weekday P.M. peak hour traffic.

\subsubsection{Ontario}

Ontario passed an SDC Resolution in 2006, with rates for water, sewer and transportation SDCs. Transportation SDC rates are predetermined based on a set price list categorized by ITE Land Use Category and Units. A transportation SDC for a single family detached home is $\$ 1,269.75$, whereas a 24 -hour convenience market is charged $\$ 16,147.50$ per thousand square feet. A motel is charged $\$ 1,471.50$ per room.

\subsubsection{Boardman}

Boardman describes its methodology for determining SDCs in Chapter 3.08.050 of the Municipal Code, specifying that for reimbursement fees the methodology must consider "the cost of then-existing facilities, prior contributions by then-existing users, the value of unused capacity, rate-making principals employed to finance public owned capital improvements, and other relevant factors identified by the council.” The methodology must also ensure that future users are charged an equitable share of cost. For improvement fees, 
the methodology must "consider the cost of projected capital improvements needed to increase the capacity of the systems to which the fee is related.”

\subsubsection{Woodburn}

Woodburn's City Ordinance 3-17.5 indicates that a methodology for determining SDCs and IDCs was set forth in “Transportation System Development Charges Study,” attached as Exhibit A to the ordinance. Ordinance 3-17.6 states that the rate schedule established based on this methodology can be adjusted based on cost changes every January. The rate change will be based on change in construction costs according to the Engineering News Record Northwest Construction Cost Index.

\subsubsection{Equity and Affordability Effects of TIFs}

Several factors must be taken into consideration when calculating the TIF in order to ensure equity. When determining methodologies for calculating TIFs, there tends to be a tradeoff between the ease of calculation and administration of fees and the preservation of equity among developers (Dueker et al. 1993). A 1987 nationwide survey of 1,000 communities found that the most common method for calculating fees was to use a flat rate (Bauman and Ethier 1987). Although using a simple formula or a flat fee is more transparent and consistent, it is less likely that a developer's payment will directly correspond to the impact that their development will have on infrastructure usage. Some developers will effectively end up paying less than they should and some will end up paying more.

In places where impact fees are calculated using a more complicated formula, it is likely that the fees will better reflect usage and that developers will pay for their actual impact on the transportation system. Depending on the situation, developers with similar projects might pay substantially different fees based on multiple factors, such as timing, physical location and other context-related circumstances. Complicated formulas are also more likely to be more equitable, but this way of calculating fees takes more time, is less transparent, and is more difficult to administer. There is also more uncertainty about what a given fee might turn out to be compared to a simpler method that yields a more predictable fee. Thus, while complex TIF formulas generally do better in assigning true cost responsibility, they tend not to be favored by developers, who, in preparing economic feasibility assessments of projects, prefer simplicity and transparency.

Another equity issue concerns the division of responsibility between new and existing development to pay for their impacts. If fees are only targeted at new development, existing development potentially will not be obliged to pay its fair share even though it may have been (and continues to be) responsible for traffic growth and wear on transportation infrastructure (Altshuler et al. 1993; Lee 1988; Levine 1994). Lee observes that existing residents have an incentive to put the financing burden on new development, and argues that just because existing users were there first, it should not give them the right to "... continue to receive urban services at their historic prices. If [for example] the demand for sewage treatment has gone up, and also its unit cost, then existing users as well as new residents should pay the higher costs... Where some valuable resource is at stake, all consumers should be faced with the same price structure, reflecting the value of the resource to the marginal user who is priced off” (1988: p.293). 
Thus it is important to consider how existing infrastructure has been paid for. It may be the case that existing development already paid for its infrastructure impact through property taxes or some other contribution (Nicholas and Nelson 1988). However, if the infrastructure was paid for in other ways, such as from transfers from higher levels of government, existing development might not have paid its fair share for the cost of infrastructure (Altshuler et al. 1993).

Nicholas and Nelson address the issue of determining the proportionate share of costs that a developer should pay, emphasizing the importance of examining the following factors (1988: $p$. 57):

- "cost of existing facilities; the means by which existing facilities have already been financed;

- the extent to which new development has already contributed, through tax assessments, to the cost of providing existing excess capacity;

- the extent to which new development will, in the future, contribute to the cost of constructing currently existing facilities used by everyone in the community or by people who do not occupy the new development;

- the extent to which new development should receive credit for providing common facilities that communities have provided in the past without charge to other developments in the service area;

- extraordinary costs incurred in serving new development; and

- the time-price differential inherent in fair comparisons of amounts paid at different times."

The economic effects of impact fees on property markets depend on who ultimately bears the cost of the fees among landowners, developers and, eventually, property owners. Empirical studies have addressed this question by estimating the rate at which impact fees are capitalized in raw land and property prices. Nelson et al. (1992) analyzed the effect of impact fees on raw land prices, and found that impact fees were nearly fully capitalized. Singell and Lillydahl (1990) estimated the effect of impact fees on residential property prices and found that the fees were more than fully capitalized. In combination, these results indicate that raw landowners benefit from the fees and that developers are able to shift the cost of the fees forward to eventual property owners and tenants. Given equilibrium in property markets, the results also indicate that existing property owners benefit from the introduction of impact fees. However, the capitalization of impact fees reduces affordability for new entrants.

\subsubsection{Legal Basis}

The courts have generally upheld the authority of local governments to impose traffic impact fees, as long as it can be shown that development is putting growth pressure on public infrastructure, and that the fee will be used to pay only for infrastructure that new development can benefit from (Dueker et al. 1993; Nicholas and Nelson 1988). One legal requirement used to judge the validity of TIFs is known as the rational nexus test (Nicholas and Nelson 1988). Under the rational nexus test, it must be demonstrated that the need for additional infrastructure is being caused by new development and not something else (Freilich and White 1994). Most states require that development must benefit substantially, although not exclusively, from TIF-funded projects. A 
second legal requirement is that fees or exactions must be "roughly proportional" to the impact of a development (Powell et al. 2006).

Local development may produce spillover effects in the form of traffic increases in neighboring communities or traffic increases on transportation facilities managed by higher levels of government. According to Altshuler et al. (1993), the courts have limited communities' ability to address such spillover effects in their traffic impact fees.

\subsection{TRANSPORTATION UTILITY/MAINTENANCE FEES}

Several counties and about 20 cities in Oregon rely on transportation utility fees (TUFs) to generate revenue for road maintenance. A transportation utility fee "allocates a portion of the recurring roadway maintenance costs to all development located within the jurisdiction limits." With TUFs, local roads are defined to be a public utility and road maintenance costs "are assigned proportionately to road usage, on the basis of trip intensity or estimated VMT" (Springer and Ghilarducci 2004, p. 1). TUFs can also be set on the basis of a property's square footage or its road frontage length. Generally, TUFs distinguish between residential land uses (which cover maintenance of local streets) and non-residential land uses (which cover maintenance of arterials).

About 10 Oregon local government TUF ordinances were reviewed for this report, and all limited fund expenditures to road preservation, maintenance, repair and operations. However, Murphy and Bartlett (2000) state that a TUF ordinance can be written in Oregon to cover capital improvements as well.

Use of TUFs have emerged in Oregon since the 1990s (Ewing 1994). Road maintenance costs have grown much faster than state gas tax revenues received by local jurisdictions. Reliance on general fund revenue to make up the difference has also been constrained by voter-approved property tax limitations.

As with fees charged for other utility services, TUFs are set to correspond to the benefits that consumers obtain from utilization of transportation infrastructure. For other utilities, these benefits, known as consumers' surplus, can be determined from direct measurement of the service consumed. With TUFs, however, consumption is not directly measurable. Given that consumption of the transportation utility is indirectly observed, the equity of TUFs may not be as great as it is for other utilities (Ewing 1994). For example, a car-less household's property could be charged the same fee as an equivalent property whose household owns multiple vehicles making many trips.

\subsection{FAIR SHARE MITIGATION}

Fair share mitigation requires developers to address the impacts of their projects by paying for or making improvements to transportation infrastructure. Usually, a traffic impact study is required to determine the effect of a proposed project on existing transportation infrastructure. Developers are then asked to mitigate the impact of their projects by contributing fees, construction, or land in order to maintain a given level of service. Legally, fair share mitigation contributions must be roughly proportional to the impact of development. As with traffic impact fees, fair share 
mitigation can be inequitable when earlier developers are held less accountable for traffic impacts (when spare capacity exists) than later developers (when capacity limits are approached).

Another potential inequity can occur when a fair share mitigation outcome benefits subsequent development. In Clackamas County, Oregon this issue has been addressed through zone of benefit recovery charges (Chapter 4.03, Clackamas County Code). Such charges are a potential outgrowth of off-site transportation improvements required by the County as a condition of development approval. The logic of the charges, as stated in the code, is as follows:

Many of these road improvements, particularly off-site, can and will be used in the future by other nearby property owners who develop or otherwise change the use of their property in a manner which creates an increased impact on road facilities. Therefore, these improvements represent a potential benefit to nearby property owners. (Chapter 4.03, Title 4-10)

In Clackamas County, the recovery of zone of benefit charges requires an application by the developer within six months of the County's approval of the improvement. Information contained in the application must include the delineation of the zone of benefit and identification of affected properties, full documentation of the cost of the improvement, and the method for allocating the designated portion of improvement costs to the affected properties. Approval of zone of benefit applications rests with the Board of County Commissioners.

Zone of benefit recovery charges cannot be levied on an affected property owner until development activity on the affected property is approved by the County. No charge is levied if no development occurs. The term of enforcement of the zone of benefit obligation for affected properties is 15 years.

The zone of benefit recovery charge code was approved by the Board of County Commissioners in 2000. To date, there has been one approved zone of benefit application, involving a developerfunded intersection improvement on OR 212. Zone of benefit recovery charges can also be applied to road improvements funded by Clackamas County, although the County has not elected to exercise this authority.

Creation of reimbursement districts also allow for recovery of a portion a of developer's cost of offsite transportation improvement from subsequent developments that benefit from the improvement. For example, the City of Woodburn approved a reimbursement district ordinance (No. 2237) in 1999, allowing a developer to recover a portion of the cost of a frontage road serving the Woodburn Company Stores (located near the I-5 Woodburn interchange) from any subsequent developments abutting the road. The reimbursement district process outlined in the City of Woodburn ordinance is similar to the zone of benefit process adopted by Clackamas County, except that the term over which cost responsibility can be assigned to subsequent development (10 years) is shorter and no reference is made to the applicability of the ordinance to publicly funded improvements. 


\subsection{TAX INCREMENT FINANCING}

Tax increment financing (TIF) is used by local governments to fund urban renewal projects, thereby encouraging redevelopment and leveraging private investment in blighted areas. TIF is sometimes used to fund transportation projects as part of an urban renewal process. When TIF is employed, an urban renewal area (URA) is created in which the assessed value of property is frozen for a set period of time, usually 20-25 years. Property taxes in the URA are collected as they would be normally, but the increment of the tax above the frozen value is then dedicated to financing capital improvements. TIF thus borrows against anticipated future tax revenue increases from expected development.

TIF has been widely employed in Oregon for urban renewal funding following a 1960 amendment to the state constitution. The Oregon Department of Revenue (2007) reports that in FY 2006-07 there were 55 active urban renewal agencies in Oregon (within 51 cities and 4 counties), administering 84 URAs. Urban renewal revenue recovered during the fiscal year by the renewal agencies totaled nearly \$165 million.

Portland has used TIF for urban renewal projects involving transportation infrastructure several times. Gateway Regional Center (658.5 acres) was designated a URA in 2001. Transportation improvements were an integral part of the Gateway URA revitalization plan. The Portland Development Commission (PDC) was authorized to raise up to \$164 million using TIF, through the expiration of the URA in 2022. Planned or completed transportation projects in the Gateway URA include light rail expansion, intersection improvements, streetscaping and transit center redevelopment.

In another TIF application to transportation, PDC designated the Interstate Corridor URA (3,769 acres) in 2000. Up to $\$ 335$ million was authorized for the area using TIF. According to the PDC, one goal of the Interstate Corridor renewal plan is to "Improve transportation corridors to encourage the use of alternative modes of travel, maintain and improve access, create a pedestrian-friendly environment, and mitigate traffic impacts associated with new growth.”

Despite successes in using TIF for selected transportation improvements, there are obstacles, including limits on the amount of a jurisdiction's land that can be classified as urban renewal areas at any one time. ORS 457.420 specifies that for municipalities with a population over 50,000, no more than $15 \%$ of the total land area or $15 \%$ of the total assessed land value can be in urban renewal areas at any one time. For municipalities with a population less than 50,000, up to 25\% of the total land or total assessed land value can be designated as urban renewal areas.

ORS Chapter 457 outlines conditions for delineating URAs in Oregon. Generally, the area in question must meet the definition of "blight." According to ORS 457.010, blighted areas are defined as "areas that, by reason of deterioration, faulty planning, inadequate or improper facilities, deleterious land use or the existence of unsafe structures, or any combination of these factors, are detrimental to the safety, health or welfare of the community." The "inadequate or improper facilities" criterion provides a statutory basis for creating a URA to finance transportation infrastructure improvements. 
TIF revenue is vulnerable to economic downturns. It is most effectively utilized when a jurisdiction's tax base is stable or growing. TIF has been criticized for being too complicated for most people to understand, resulting in a lack of public accountability and uncertainty about how much other taxing jurisdictions are affected (Portland Development Commission 2005). TIFfunded urban renewal has been criticized in Portland because the terms of its urban renewal districts have often been extended even after blight is no longer apparent (City Club of Portland 2005). TIF has been criticized for limiting the growth of local general fund revenues, otherwise known as "diluting the soup," which occurs when renewal-leveraged increases in demand for public services must be met without corresponding increases in property tax revenue, given the frozen tax base (City Club of Portland 2005). Lastly, a unique statutory feature of urban renewal in Oregon's is that the creation of a URA does not require formal consent of all affected taxing jurisdictions.

\subsection{LOCAL IMPROVEMENT DISTRICTS}

Local improvement districts (LIDs) are entities created when a group of property owners who need infrastructure improvements organize to pay for its costs. ORS 223 specifies the rules for creation of LIDs. A LID lasts only until the improvement is completed and the debt obligation has been met. LIDs are usually created in order to raise capital for smaller projects, such as installing sidewalks. However, a LID can also be formed to finance more substantial infrastructure improvements. For example, a LID was created in Portland to contribute to the financing of the Portland Streetcar project. Another was created to contribute financing to Portland's transit mall improvements. The City of Wilsonville formed a LID to fund widening of Wilsonville Road in coordination with ramp improvements at the I-5 interchange.

Determining the financial obligation of property owners in a LID can be based on a variety of methods, including frontage length and property size (usually the case for residential property), or trip generation (often the case for commercial property). The method can also be modified to account for the distribution of expected benefits from an improvement. For example, the financial obligations of property owners in the Portland Streetcar and transit mall improvement LIDs decline with distance from the improvements.

\subsection{VALUE CAPTURE}

Value capture is a broad term describing the use of various methods for financing improvements based upon the value infrastructure improvements add to benefited properties. Provision of transportation infrastructure and transportation services confers benefits to system users and to properties with access to these services. Access to transit service is particularly beneficial within congested urban transportation systems. The capitalization of such access benefits increases property values for residents and businesses, and provides a "... catalyst for more clustered development patterns" (Smith and Gihring 2006, p. 4).

Value capture financing mechanisms are designed to recover some of the capitalized benefit in order to fund transportation improvements. The mechanisms actually employed can include tax increment, LID, and other forms of financing. For transit projects, value capture works by "taxing a portion of the additional value of adjacent properties that result from transit accessibility" (Smith 
and Gihring 2006, p. 4). A substantial amount of empirical information provides evidence of transit benefit capitalization, especially for rail transit improvements (Cervero et al. 2004; French Development Agency and Ministry of Ecology, Energy, Sustainable Development and the Sea 2009; Huang 1996).

Value capture financing has been successfully employed in many situations, including in Hong Kong, where transit system capital costs are covered by revenue raised through value capture financing (Smith and Gihring 2006). In Hong Kong's case, however, the revenue stream is greatly enhanced by rents received from leases of state-owned property near transit stations (AECOM Consulting 2007).

TriMet's MAX Yellow Line relied in part on value capture financing through TIF funds from the Interstate Corridor URA. Value capture financing can also occur through the formation of a LID. Moreover, it is not unusual for transit infrastructure projects to involve multiple value capture financing mechanisms. Financing for the Portland Streetcar, for example, involved both TIF and LID funds, while financing for TriMet's light rail extension from the Gateway Transit Center to Portland International Airport (PIA) included TIF funds from the Gateway URA, proceeds from the sale of development rights at the Cascade Station location on PIA property, and a commitment of future employment tax revenues from TriMet (Smith 2001).

One concern with value capture financing is the prospect that benefits will not be uniformly experienced by all property owners who are included (and pay taxes) in the district. Those most likely to benefit reside closest to transit access points. LID financing obligations can be tailored to reflect spatial variations in expected property value benefits, while TIF relies more generally on the overall portfolio of projects in an urban renewal plan to achieve spatial correspondence of costs and benefits. Also, because future land development potential is uncertain, value capture revenue stream servicing debt may be considered more speculative by capital markets, thus increasing financing costs (AECOM Consulting 2007).

While applications of value capture financing have mainly been limited to local governments and have been primarily employed in financing transit system improvements, the concept is also relevant to financing state highway improvements. One example is Batt's (2001) analysis of a \$128 million improvement along a nine mile corridor of I-87 near Albany, New York. He estimated that the present value of capitalized benefits from the I-87 improvement to properties within two miles of the corridor would total over $\$ 3.7$ billion.

In 2007, the Texas Legislature authorized value capture financing of state highway improvements. The provisions of the legislation call for the creation of transportation reinvestment zones (TRZs) to delineate properties whose value would be affected by transportation improvements. The legislation envisioned a tax increment financing mechanism for capturing the improvement-related benefits to existing development, and allow for application of improvement-specific impact fees to capture the benefits to new development (Vadali et al. 2009). There is a key difference between Texas' value capture tax increment mechanism and tax increment financing in urban renewal. In the Texas program, revenues are drawn from the increment above a projected trend tax base, while in urban renewal, revenues are drawn from the increment above a frozen tax base. In the Texas program, the trend represents the expected evolution of the tax base without the transportation improvement. 
Although there is growing interest in value capture financing of state transportation improvements, it should also be acknowledged that most state governments are now more than a century removed from the general practice of levying taxes on real property. Reaching agreement with local governments on apportioning locally levied taxes (related to capitalized benefits from state facility improvements) would be difficult. Vadali et al. (2009) emphasize that a general framework for coordinated planning among state and local entities must be in place, and that specific financing agreements need to be in place early in the project planning process in order to capture “anticipatory” gains in property value.

\subsection{TRANSPORTATION IMPROVEMENT DISTRICTS}

A transportation improvement district (TID) is created by designating an area as a special funding district in order to provide transportation infrastructure. The scope and authority of TIDs varies from state to state, but they are typically undertaken in high growth areas where infrastructure needs cannot be met through the capital programs of local or state transportation departments. TID funds are obtained from assessments on existing property in the district. While property values are typically used as the basis of assessments, the revenues collected are not interpreted as property taxes. Instead, "they are considered non-ad valorem assessments based on benefits to the property from district expenditures, because benefits are presumed to be proportional to property values" (AECOM Consulting 2007, p. 3).

One of the principal advantages of TID financing is that it promotes regional cooperation among local governments and between governments and commercial property owners to achieve improvements that would be much more difficult or impossible to undertake individually. Thus, TIDs promote longer-range comprehensive transportation planning.

Although TIDs have been primarily concerned with financing improvements to local transportation infrastructure, there are instances where they have been organized to finance improvements in state transportation facilities. One of the earliest examples was the 1981 creation of Denver's Joint Southeast Public Improvement Association (JSPIA) TID among commercial property owners located in a five mile suburban corridor along I-25 (JSPIA no date). Over time, funds recovered by the JSPIA TID were used by the Colorado Department of Transportation to cover two-thirds of the cost of improvements to five interchanges and one overpass located in the district.

A second example is the 1987 formation of the Route 28 Highway TID in Loudoun and Fairfax Counties, Virginia. The purpose of this TID was to recover revenue from commercial property assessments to accelerate planned improvements to State Route 28, to provide better access to Dulles International Airport. Under a contract with the TID, Loudoun and Fairfax Counties agreed to levy an additional tax assessment, collect the tax, and transfer the revenue to the Commonwealth Transportation Board. TID tax revenue was combined with county revenue from state gas tax allocations to service debt on bonds issued by the state to finance the Route 28 improvements.

A final example is the creation of a TID in Port St Lucie, Florida to wholly finance construction of an interchange on the Florida Turnpike (Tollroadsnews 2007). In this case, the TID consisted of two large developers, whose intentions were to improve Turnpike accessibility to their nearby projects. The TID provided \$7.8 million of the \$20.0 million cost of the project up front, with the 
remainder consisting of borrowed funds to be repaid by a levy imposed on property sales from their developments. The TID was administered by the City of Port St. Lucie.

\subsection{TRANSPORTATION CONCURRENCY}

Transportation concurrency is "a growth management strategy aimed at ensuring that transportation facilities and services are available 'concurrent' with the impacts of development” (CUTR 2007, $p$. 5). Prior to development, a jurisdiction must determine the adequate level of service for an area and then assess whether infrastructure demands created by new development would exceed existing capacity. If there is insufficient existing capacity, “... the developer must provide the necessary facility or service improvements to proceed, provide a monetary contribution towards such improvements, or wait until government provides the necessary improvements” (Williams 2006, p.47).

Concurrency is being practiced in Maryland, New Hampshire, Washington, and Florida. The state of Florida "mandates adequate public facilities through its concurrency requirement, forbidding the issuance of a land development permit that would cause level of service standards to fall below those adopted in the Comprehensive Plan” (Freilich and White 1994, p.16).

A problem faced by many local governments in Florida has been the absence of a transportation concurrency management system. Trying to administer transportation concurrency without systematic information has not worked very well (CUTR 2007). One of the key problems with concurrency is that it gives earlier developers the advantage of being able to use up capacity without paying, whereas later developers are penalized.

Downs (2003) concludes that there are several undesirable consequences of Florida's transportation concurrency program. First, he argues that concurrency encourages developers to seek out locations where existing transportation infrastructure can support additional growth. These locations are often found on the periphery of metropolitan areas. Thus, Downs contends that concurrency promotes sprawl. Second, he claims that developers' option of "buying out" of concurrency requirements, coupled with traffic impact fees, substantially erodes housing affordability. Lastly, he argues that concurrency can never be reasonably achieved in the present era of widespread traffic congestion. Referring to the "triple convergence" phenomenon developed in his classic paper (Downs 1962), Downs claims that capacity improvements made to satisfy concurrency requirements will be quickly absorbed by rescheduled, diverted, and induced travel.

In extreme cases, transportation concurrency requirements can substantially curtail development when the cost of absorbing transportation improvements make development projects uneconomic.

Transportation concurrency is not practiced in Oregon. However, provisions of the 2005 amendments to the TPR relating to zoning changes and comprehensive plan amendments effectively require that concurrency be achieved within the time horizon of a TSP. 


\subsection{TRANSPORTATION CORPORATIONS}

Transportation corporations are nonprofit organizations formed by citizens and local governments to plan and develop transportation projects. The ability of transportation corporations to work on projects varies from state to state, and currently only a few states allow for the establishment of transportation corporations, including Texas, Missouri and Florida (Williams 2006). Oftentimes transportation corporations work to secure financing for planned projects that have wide public support, in order to speed up the programming timetable. In Missouri, transportation corporations can raise money by soliciting donations, issuing tax-exempt bonds, and charging and collecting tolls, but they are not allowed to collect taxes (MODOT 2009).

An example from Missouri is the Highway 63 Transportation Corporation, formed in 2000 to raise funds for upgrading a 22-mile state highway segment connecting the cities of Macon and Kirksville (National Council for Public-Private Partnerships 2009). Corporation membership included private residents, an area chamber of commerce, three counties, and four cities. Corporation funds for the project were obtained from a voter-approved sales tax increase (in Kirkland) along with voluntary contributions from the other Corporation members.

\subsection{LOCAL OPTION TRANSPORTATION TAXES}

Local option transportation taxes (LOTTs) have become an increasingly popular means of generating revenue as traditional funding sources shrink and local governments take on greater responsibility in transportation infrastructure funding (Goldman and Wachs 2003). Goldman and Wachs define a LOTT as "a tax that varies within a state, with revenues controlled at the local or regional level, and earmarked for transportation-related purposes” (2003, p. 21). These taxes mark a shift in transportation finance away from the user charges (i.e., gas taxes and vehicle registration fees) that have traditionally been employed to fund transportation infrastructure improvements.

With respect to the transportation planning process, the emergence of LOTTs is also seen as a shift from "planning bureaucracies and toward mechanisms of direct democracy" (Goldman and Wachs 2003, p.20). Since 1962, regional transportation planning in metropolitan areas has been the responsibility of metropolitan planning organizations (MPOs). However, when it comes to funding transportation projects within metropolitan areas, only California and Nevada give MPOs direct authority over the use of local option taxes (Goldman and Wachs 2003).

LOTTs include fuel taxes, vehicle registration fees, sales taxes, and income, payroll and employer taxes. In Oregon, local option gas taxes are imposed in 2 counties and 17 cities (League of Oregon Cities 2007). In their research on LOTTs nation-wide, Goldman and Wachs (2003) found that sales taxes are the most commonly employed LOTT. The Portland area was among the first regions in the country to adopt a LOTT in 1969 (in the form of a payroll tax), dedicated to supporting its transit provider's operating costs. Other transit supporting LOTTs include a sales tax in San Francisco (passed in 1969), and a mortgage recording tax in New York (also passed in 1969) (Goldman and Wachs 2003). Goldman and Wachs offer several reasons why LOTTs have become increasingly popular, including the revolt against property taxes; shrinking gas tax revenues; and the rise in highway construction and maintenance costs. 
The Oregon Legislature limited the ability of local governments in Oregon to introduce gas taxes or amend existing gas taxes in the 2009 session. The Legislature enacted HB 2001, which prohibits local governments from enacting new gas tax provisions or from amending existing gas tax provisions until January 2014. Subsequently, new or amended provisions related to local option gas taxes will be allowed, subject to voter approval.

\subsection{STATE TRANSPORTATION INFRASTRUCTURE BANKS}

In recent years, state transportation departments and local governments have increasingly turned to debt financing of their infrastructure improvement programs (Henken 2009). While a full review of the debt instruments employed by state and local governments is beyond the scope of this report (see Henken 2009; NSTIFC 2009), state infrastructure banks (SIBs) are addressed here because they offer a potentially important source of financing for local transportation improvements in Oregon.

SIBs were authorized on a pilot basis by the National Highway System Designation Act of 1995. Oregon was one of 10 states selected in 1996 by the Secretary of Transportation for inclusion in the SIB pilot program. In 1997, the Oregon Legislature established the Oregon Transportation Infrastructure Fund (OTIF), and the Oregon Transportation Infrastructure Bank (OTIB) operates as part of this fund. The Legislature subsequently expanded and updated provisions of OTIB, which operates under the authority of ORS $367.010-367.060$. OTIB operation is also subject to an agreement between ODOT, the Federal Highway Administration (FHWA) and the Federal Transit Administration (FTA).

Federal funds, state funds, and funds from the sale of revenue bonds can be used to capitalize OTIB. State matching of federal funds is required. The OTC initially designated funds from the Oregon Highway Trust Fund (OHTF) as state match. The Oregon Constitution limits the use of the OHTF to highway projects. FTA funds were thus subsequently matched by state funds from the Petroleum Violation Escrow (PVE) account, established in a settlement agreement related to oil company violations of federal oil price caps that were in place from 1973 to 1981.

OTIB provides loans for transportation projects to eligible borrowers, which include cities, counties, port authorities, transit districts, special districts, tribal governments, state agencies, and private for-profit and not-for-profit entities in Oregon. Eligible projects include highway projects, transit capital projects and bikeway or pedestrian access projects. OTIB loans can be used to cover up to $100 \%$ of a project's costs.

OTIB is administered by ODOT and the OTC. The OTC has final loan approval authority. Projects are selected for OTIB loans based on ratings by staff and recommendations of a regional advisory committee. Project ratings are taken into consideration by ODOT's Chief Financial Officer, who is responsible for recommending loan approval to the OTC. Interest rates for loans depend on the type of loan taken out and on the credit rating of the applicant. Repayment of OTIB loans must begin within five years of project completion and must be complete 30 years from project completion or at the end of the project's lifespan, if it is less than 30 years. 
OTIB's capitalization reached $\$ 50$ million in 2007 and it had not yet issued debt in order to raise additional capital. FHWA (2007) reported that as of September 2006, OTIB had completed 19 loan agreements totaling \$34.4 million and had disbursed \$25.1 million. Project level loan information was not reported on OTIB's web site or in its annual reports. A web search did identify several local government transportation projects whose financing included OTIB loans. Clackamas County has been approved for several OTIB loans, including a loan for Sunnyside Road Phases 2 and 3, as well as another for bridge and road projects. Clackamas County plans to use transportation SDC revenues to service its OTIB loans. The Rogue Valley MPO reported several regional projects with OTIB loan funding, including an environmental assessment undertaken in connection with the I-5 Fern Valley interchange improvement project and several rail crossing improvements on OR 99 in Central Point.

\subsection{SUMMARY}

Table 3.1 provides a summary of the principal features of the infrastructure financing mechanisms covered in this chapter. The table also summarizes the main strengths and weaknesses of the financing mechanisms, and provides examples (where possible) of their applicability in Oregon. 
Table 3.1: Summary Features of Alternative Financing Mechanisms

\begin{tabular}{|c|c|c|c|c|}
\hline Mechanism & How It Works & Strengths & Weaknesses & Uses in Oregon \\
\hline $\begin{array}{l}\text { Traffic Impact } \\
\text { Fees / System } \\
\text { Development } \\
\text { Charges }\end{array}$ & $\begin{array}{l}\text { A one-time fee charged by local } \\
\text { government on new development, } \\
\text { intended to pay for expansion of } \\
\text { public facilities made necessary } \\
\text { by development. Fee must be } \\
\text { roughly proportionate to the } \\
\text { infrastructure cost occasioned by } \\
\text { the impacts of the development } \\
\text { and there must be a rational } \\
\text { connection between the } \\
\text { development and the use of the } \\
\text { fee. }\end{array}$ & $\begin{array}{ll}\text { - } & \text { Equity between big and } \\
\text { small developers } \\
\text { - } & \text { Support from big } \\
\text { developers due to } \\
\text { predictability, consistency } \\
\text { and fairness } \\
\text { - } \quad \text { Reduces government } \\
\text { borrowing and debt } \\
\text { - } \quad \text { Manages growth } \\
\text { Promotes long-term } \\
\text { planning } \\
\text { Credits can be given to } \\
\text { developers who contribute } \\
\text { to transportation facilities } \\
\text { in other ways }\end{array}$ & $\begin{array}{ll}\text { - } & \text { Fee capitalization reduces } \\
\text { - } & \text { housing affordability } \\
& \text { Flat fee per dwelling unit } \\
\text { - } & \text { leads to vertical inequity } \\
\text { Potential for inequity } \\
\text { between existing \& new } \\
\text { residents } \\
\text { - }\end{array}$ & $\begin{array}{l}\text { Used extensively } \\
\text { Fees vary widely across } \\
\text { local jurisdictions } \\
\text { Used by City of } \\
\text { Woodburn for local } \\
\text { contribution to I-5 } \\
\text { interchange } \\
\text { improvement }\end{array}$ \\
\hline $\begin{array}{l}\text { Fair Share } \\
\text { Mitigation }\end{array}$ & $\begin{array}{l}\text { Requires developers to mitigate } \\
\text { the transportation impacts of their } \\
\text { projects by contributing fees, } \\
\text { construction, or land for } \\
\text { improvements to infrastructure } \\
\text { when increased traffic resulting } \\
\text { from their development projects } \\
\text { leads to a lack of capacity, based } \\
\text { on a previously established level } \\
\text { of service standards. A traffic } \\
\text { impact study is usually required to } \\
\text { estimate the magnitude of impact } \\
\text { requiring mitigation. }\end{array}$ & $\begin{array}{l}\text { - } \\
\text { Encourages } \\
\text { comprehensive planning } \\
\text { Achieves } \\
\text { “proportionality” by } \\
\text { ensuring correspondence } \\
\text { between traffic impacts } \\
\text { and mitigation actions. }\end{array}$ & $\begin{array}{l}\text { Potentially inequitable; } \\
\text { favors earlier over later } \\
\text { developers. Later and } \\
\text { larger development pays } \\
\text { more } \\
\text { - } \quad \text { Difficult and costly to } \\
\text { administer } \\
\text { - Each case is separately } \\
\text { determined; outcomes are } \\
\text { less predictable and } \\
\text { consistent } \\
\text { Difficult to coordinate with } \\
\text { local governments }\end{array}$ & $\begin{array}{l}\text { Increasingly used by } \\
\text { ODOT and local } \\
\text { governments to } \\
\text { maintain safety \& } \\
\text { preserve capacity }\end{array}$ \\
\hline
\end{tabular}




\begin{tabular}{|c|c|c|c|c|}
\hline Mechanism & How It Works & Strengths & Weaknesses & Uses in Oregon \\
\hline $\begin{array}{l}\text { Tax Increment } \\
\text { Financing }\end{array}$ & $\begin{array}{l}\text { A renewal district is created in } \\
\text { which the assessed value of } \\
\text { property is "frozen” for property } \\
\text { tax distribution purposes for a set } \\
\text { period of time, usually } 20-25 \\
\text { years. The increment of taxes } \\
\text { collected above the frozen value } \\
\text { is then used by the local } \\
\text { government to finance capital } \\
\text { improvements. TIF borrows } \\
\text { against anticipated future tax } \\
\text { revenue. }\end{array}$ & $\begin{array}{ll}\text { - } & \text { Stimulates private } \\
\text { investment and facilitates } \\
\text { public-private } \\
\text { partnerships } \\
\text { - } \quad \text { Can revitalize depressed } \\
\text { areas } \\
\text { - } \\
\text { Does not increase tax } \\
\text { burden on property } \\
\text { owners }\end{array}$ & 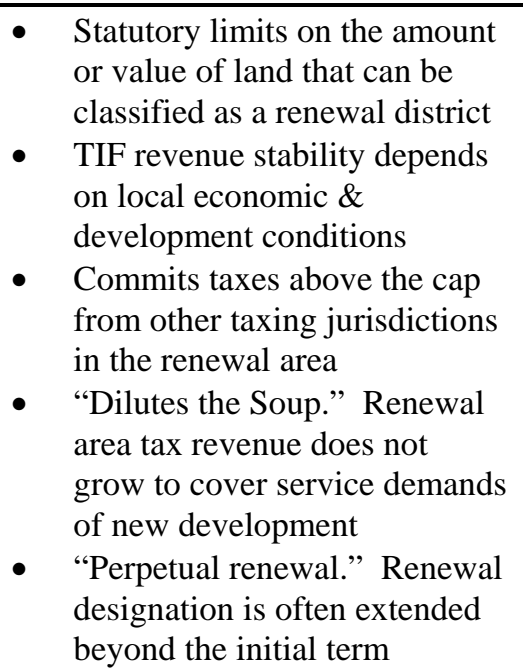 & $\begin{array}{l}\text { Used extensively } \\
\text { throughout Oregon } \\
\text { following a } 1960 \text { state } \\
\text { constitution amendment } \\
\text { TIF funds have often } \\
\text { been used for local } \\
\text { transportation } \\
\text { infrastructure } \\
\text { improvements }\end{array}$ \\
\hline $\begin{array}{l}\text { Local } \\
\text { Improvement } \\
\text { Districts / } \\
\text { Transportation } \\
\text { Improvement } \\
\text { Districts }\end{array}$ & $\begin{array}{l}\text { A special funding district is } \\
\text { created to improve infrastructure } \\
\text { within a specific area. A local } \\
\text { government and other government } \\
\text { agencies work together to make a } \\
\text { transportation project happen. } \\
\text { Authority varies from state to } \\
\text { state, but LIDs \& TIDs usually act } \\
\text { as separate entities with the power } \\
\text { to authorize tax levies, issue } \\
\text { revenue bonds, and create } \\
\text { contracts for transportation } \\
\text { improvements. }\end{array}$ & 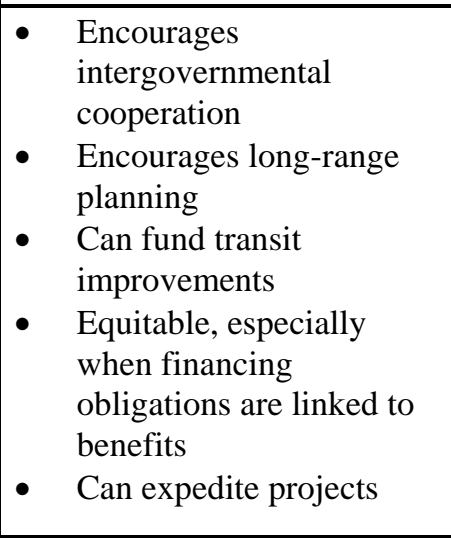 & $\begin{array}{l}\text { Difficult to establish \& } \\
\text { administer }\end{array}$ & $\begin{array}{l}\text { Wilsonville Rd. } \\
\text { improvements at I-5 } \\
\text { interchange } \\
\text { Portland Streetcar } \\
\text { Portland Transit Mall } \\
\text { Improvements }\end{array}$ \\
\hline
\end{tabular}




\begin{tabular}{|c|c|c|c|c|}
\hline Mechanism & How It Works & Strengths & Weaknesses & Uses in Oregon \\
\hline $\begin{array}{l}\text { Transportation } \\
\text { Concurrency }\end{array}$ & $\begin{array}{l}\text { Prior to development, the } \\
\text { jurisdiction determines adequate } \\
\text { level of service for the area and } \\
\text { then determines whether traffic } \\
\text { from new development would } \\
\text { exceed existing capacity. If there } \\
\text { is not enough capacity the } \\
\text { developer has to pay for necessary } \\
\text { improvements or wait to develop } \\
\text { until government funds } \\
\text { improvements. }\end{array}$ & $\begin{array}{l}\text { Ensures compatibility of } \\
\text { land use \& infrastructure } \\
\text { planning in the } \\
\text { development process } \\
\text { - Discourages growth in } \\
\text { places with infrastructure } \\
\text { limitations }\end{array}$ & $\begin{array}{ll}- & \begin{array}{l}\text { Equity concerns about earlier } \\
\text { developers using up available } \\
\text { capacity }\end{array} \\
\text { - } & \text { Achieves incremental } \\
\text { improvement rather than } \\
\text { encouraging comprehensive } \\
\text { planning } \\
\text { - } \\
\text { Potentially negative effects on } \\
\text { housing affordability \& sprawl }\end{array}$ & $\begin{array}{l}\text { Not applicable in } \\
\text { Oregon, although } \\
\text { negotiated mitigation } \\
\text { agreements \& TPR } \\
\text { review of } \\
\text { comprehensive plan } \\
\text { amendments can have } \\
\text { similar long run effects } \\
\\
\text { Applies extensively in } \\
\text { Florida \& Washington }\end{array}$ \\
\hline $\begin{array}{l}\text { Transportation } \\
\text { Corporations }\end{array}$ & $\begin{array}{l}\text { Transportation corporations are } \\
\text { nonprofit corporations formed by } \\
\text { citizens, businesses, and local } \\
\text { governments to plan, promote, } \\
\text { and finance transportation } \\
\text { projects. They can raise money in } \\
\text { a variety of ways depending on } \\
\text { state-specific rules, including } \\
\text { donations, issuing tax-exempt } \\
\text { bonds, and charging and } \\
\text { collecting tolls. }\end{array}$ & $\begin{array}{ll}- & \text { Expedites public projects } \\
\text { - } & \text { Flexible funding } \\
\text { - } & \text { The corporation assumes } \\
\text { debt liability, not the local } \\
\text { government }\end{array}$ & $\begin{array}{ll}- & \text { Success depends on wide local } \\
& \text { support } \\
\text { - } & \text { Financing may require voter- } \\
& \text { approved local tax increases }\end{array}$ & $\begin{array}{l}\text { No experience in } \\
\text { Oregon to date }\end{array}$ \\
\hline $\begin{array}{l}\text { Local Option } \\
\text { Transportation } \\
\text { Taxes (LOTTs) }\end{array}$ & $\begin{array}{l}\text { A tax at the local or regional } \\
\text { level, approved by voters, that is } \\
\text { used for transportation-related } \\
\text { purposes. Can take the form of a } \\
\text { fuel tax, sales tax, vehicle tax, } \\
\text { property tax, utility fees, income } \\
\text { tax, payroll tax, employer tax and } \\
\text { others. }\end{array}$ & $\begin{array}{ll}- & \text { Increasingly popular } \\
\text { across the country } \\
\text { - } \\
\text { High level of public } \\
\text { participation / input from } \\
\text { voters }\end{array}$ & $\begin{array}{l}\text { Lack of flexibility regarding } \\
\text { spending of funds; need to } \\
\text { spend the money the way } \\
\text { voters approved } \\
\text { Depending on type of tax, } \\
\text { level of funding may not be } \\
\text { stable } \\
\text { - } \text { LOTT-financed projects may } \\
\text { not be well coordinated with } \\
\text { local or state transportation } \\
\text { improvement plans }\end{array}$ & $\begin{array}{l}\text { Portland region among } \\
\text { the first in the country } \\
\text { to pass a LOTT in } 1969 \\
\text { (payroll tax for transit) } \\
17 \text { Oregon cities \& } 2 \\
\text { counties have a local } \\
\text { option gas tax }\end{array}$ \\
\hline
\end{tabular}




\begin{tabular}{|c|c|c|c|c|}
\hline Mechanism & How It Works & Strengths & Weaknesses & Uses in Oregon \\
\hline Value Capture & $\begin{array}{l}\text { Financing that "captures" the } \\
\text { capitalization of infrastructure } \\
\text { improvement benefits in property } \\
\text { values in order to service debt. } \\
\text { Used primarily for transit rail } \\
\text { projects. Finance mechanisms } \\
\text { include TIF, LID, parking } \\
\text { revenues, etc. }\end{array}$ & $\begin{array}{ll} & \text { Distribution of financing } \\
\text { liability is benefit-based } \\
\text { - } \\
\text { Leverages private } \\
\text { development }\end{array}$ & $\begin{array}{l}\text { The link between liability and } \\
\text { benefit is stronger for some } \\
\text { VC mechanisms (e.g., LIDs) } \\
\text { than others (TIF, parking } \\
\text { revenue) }\end{array}$ & $\begin{array}{l}\text { Portland Streetcar; } \\
\text { Portland transit mall } \\
\text { improvements; } \\
\text { MAX airport extension; } \\
\text { MAX yellow line }\end{array}$ \\
\hline $\begin{array}{l}\text { State } \\
\text { Infrastructure } \\
\text { Bank }\end{array}$ & $\begin{array}{l}\text { Provides low interest loans to } \\
\text { local government, usually for } \\
\text { large infrastructure projects. Debt } \\
\text { can be serviced by revenues from } \\
\text { impact fees or other local } \\
\text { financing methods. }\end{array}$ & $\begin{array}{l}\text { Useful for large projects } \\
\text { that are beyond "pay-as- } \\
\text { you-go" capability } \\
\text { - } \quad \text { Responds to acute } \\
\text { capacity problems } \\
\text { - Favorable financing terms } \\
\text { - Hedges against rising } \\
\text { construction costs - "gets } \\
\text { the work done at today's } \\
\text { dollars" } \\
\text { - Helps to meet local match } \\
\text { in leveraging non-local } \\
\text { funding }\end{array}$ & $\begin{array}{l}\text { Debt service obligations can } \\
\text { limit future options } \\
\text { Use of OR highway trust fund } \\
\text { capital is limited to highway } \\
\text { projects; non-highway projects } \\
\text { must access other capital } \\
\text { sources }\end{array}$ & $\begin{array}{l}\text { Clackamas Co. - } \\
\text { Springwater \& Stafford } \\
\text { Rd. bridges; Sunnyside } \\
\text { Rd. \& } 172^{\text {nd }} \text { Ave. } \\
\text { improvements } \\
\\
\text { Rogue Valley MPO - } \\
\text { I-5 Fern Valley } \\
\text { Interchange } \\
\text { environmental } \\
\text { assessment; } \\
\text { Central Point OR } 99 \\
\text { rail crossings }\end{array}$ \\
\hline
\end{tabular}




\subsection{EVALUATION OF FINANCING MECHANISMS}

Most of the mechanisms presented in the previous section have been extensively employed by local governments in financing transportation and other infrastructure improvements. Ideally, the choice of financing mechanism should reflect the context in which it is applied. However, assessments of the distributional correspondence between transportation financing costs and improvement benefits indicate that the choice of financing mechanism has often seemed arbitrary. For example, in their assessment of financing partnerships for Texas state highway improvements, Persad et al. conclude that “... there is no pattern or consistency for selection of financing tools. It appears that in each case, whatever method of financing was available or could be gathered was used. ...No planning tools were used in targeting the most financially suitable repayment mechanism” (2008: 70). Although the expedient or available option may sometimes be the only feasible choice, it is nevertheless worthwhile to consider how alternative financing mechanisms fare with respect to established public finance criteria.

When considering financing mechanisms to generate revenue for public facility improvements, there are several general principles that should be taken into account. According to principles of public finance theory, there are six features that characterize an optimal tax (Musgrave and Musgrave 1989). These features, listed below and further discussed in the following sections, should be considered in evaluating alternative financing mechanisms for interchange area infrastructure improvements.

- Yield/Revenue Potential - Does the financing mechanism have the ability to generate the necessary revenue within the specified time frame? Stability of the revenue stream and flexibility of the financing mechanism should also be considered.

- Equity - Is the financing mechanism perceived by those who bear the financial responsibility as being reasonably fair?

- Efficiency - Does the financing mechanism promote economic efficiency?

- Administrative Ease - Can the financing mechanism be administered relatively easily and cost-effectively?

- Transparency - Is the financing mechanism relatively transparent and easy for the public to understand?

- Political and Legal Feasibility - Are there political or legal obstacles to implementation of the financing mechanism?

Overall, Musgrave and Musgrave characterize a good tax system as being “...designed so as to meet the requirements of equity in burden distribution, efficiency in resource use, goals of macro policy, and ease of administration” (1989, p. 217). 


\subsection{YIELD/REVENUE POTENTIAL}

This may be the most important consideration: is it possible for a particular financing mechanism to generate revenue that is sufficient to meet funding needs? If the mechanism cannot generate sufficient revenue in the specified timeframe, it does not make sense to consider it. In turn, this leads to the question of how easy or certain it will be to predict the revenue yield of the mechanism under consideration.

The predictability of revenue streams is particularly important when debt financing is employed. Should the revenue stream earmarked for servicing debt prove insufficient, other sources must be tapped. For example, in 1999, Hamilton County, Ohio issued 30 year revenue bonds to finance the construction of two new stadiums for their professional sports franchises. A voter-approved sales tax increase provided revenue to service the bonds. However, construction costs exceeded budgeted amounts and the yield of the sales tax increase has been substantially below what had been forecast. Thus, Hamilton County now faces a need to draw resources from its general fund and cut other general fund expenditures - to meet its stadium debt service obligations (Belson 2009).

Evaluation based on stability relates to the financing mechanism's ability to produce a revenue stream with a cyclicality that is less pronounced than the general business cycle. In general, it is agreed that revenue sources whose yields are less volatile than the business cycle are preferable to those that are more volatile. For example, revenue streams derived from the property tax tend to be much less volatile than revenue streams obtained from charges on development activity. Thus, from the standpoint of stability, LID-based financing would be preferable to TIF financing, and TIF financing would be preferable to traffic impact fees. In terms of flexibility, the financing should be evaluated with respect to whether it can it be applied to a wide range of investments and redirected to different uses if appropriate.

\subsection{EQUITY}

Two aspects of equity are relevant to the assessment of alternative financing mechanisms. The first, known as horizontal equity, deals with the principle that those with equal means should pay equally. With ad valorem taxes, such as property taxes, horizontal equity is achieved when owners of property with equal market values face equal tax liabilities. In this case, achieving horizontal equity depends on effective administration of the property assessment process (Doering 1977). The coefficient of dispersion of the ratio of assessed to market values is a widely accepted measure of horizontal equity.

Prior to the 1990s, property assessments in Oregon were characterized by a high level of horizontal equity compared to other states, as documented in the Census of Governments (e.g., U.S. Bureau of the Census 1982). However, property tax limitation measures approved by Oregon voters in the 1990s have substantially uncoupled the relationship between assessed values and market values. Thus, properties with similar market values may no longer carry similar assessed values. The loss of horizontal equity as a result of the tax limitation measures has not been documented, as the Census of Governments no longer reports state assessment performance. The Oregon Department of Revenue, which has oversight responsibility for county assessment and taxation administration, 
documents the relationship between sale prices and real market value estimates (pursuant to its Measure 5 mandate). Thus horizontal equity of property tax liabilities in Oregon is currently unknown. An Interim Legislative Task Force is examining systematic patterns of assessments in relation to market values in five Oregon counties to determine the extent to which horizontal equity has deteriorated.

Horizontal equity does not reflect one's ability to pay a tax in relation to the value of benefits received. The consideration of one's ability to pay relates to vertical equity, and in general discourages the utilization of regressive financing tools that place a disproportionate burden on those with less ability to pay. The sales tax is frequently cited as an example of a horizontally equitable but vertically regressive tax. Although all consumers are charged equally across all products subject to the tax, the incidence of the sales tax falls more heavily on lower income consumers because they spend a greater share of their income on taxed products. Similarly, the gas tax can be characterized as horizontally equitable but vertically regressive, given that it is insensitive to motorists’ ability to pay.

With respect to property taxation, conventional assessment practices are also more likely to result in vertically regressive tax liabilities (Paglin and Fogarty 1972; Reinmuth 1977). However, in contrast to the negative effects of Oregon's property tax limitations on horizontal equity, it is not evident that the measures have had a negative effect on vertical equity.

On a related note, it is important to consider the probable tax incidence, or who actually ends up paying for the tax or fee, and its effect on equity. For example, critics of development impact fees contend that most of the burden of the fee (i.e., incidence) is passed on from the developer to the buyer. Unless the fee is scaled to correspond to the value of the property developed, the outcome will also be regressive.

The issue of equity between existing and future development is a major concern with many financing mechanisms because several are designed to obligate existing development while others are designed to obligate future development. Thus it is important to determine the extent to which newcomers are responsible for transportation improvement costs that wouldn't have arisen otherwise, so that such costs can be fairly apportioned to them.

Equity issues also arise with financing mechanisms involving voter approval or collective agreement (e.g., LIDs, sales tax increases, local option gas taxes). As Downs (1957) observes, the outcome of such processes tend to correspond to the median preference of voters or collective agreement participants. When preferences vary widely, a non-trivial share of the involved parties can be disaffected by the outcome.

Lastly, geographic equity should be evaluated in terms of how well a financing mechanism is able to reflect a spatial correspondence between the benefits and financing liabilities of transportation improvements. For example, most of the accessibility benefits of interchange area transportation improvements are likely to be contained within designated IAMP areas. However, the travel shed for interchange facilities usually extends well beyond IAMP areas, indicating that benefit spillovers from interchange improvements are also likely and ought to be reflected in financing responsibility. 


\subsection{EFFICIENCY}

In evaluating the efficiency of financing mechanisms, there are several relevant considerations, including whether or not a particular tool will encourage both efficient investment (production) and

efficient usage (consumption). A financing mechanism that promotes efficiency has the potential to reduce the size of the necessary investment in transportation improvements. Another efficiency consideration is the extent to which the mechanism is able to account for all costs that follow from the use of transportation facilities, including externalities. Generally, efficiency is achieved when all costs are allocated in accordance with use.

Beyond cost allocation, infrastructure development can be considered more or less efficient depending on the magnitude of benefits created from the resources deployed. The larger the benefits that are created from a given commitment of resources, and the lower the total costs of providing those benefits, the more efficient is the investment in question. If part of the cost is shifted elsewhere or if the facility is allowed to functionally deteriorate, the financing mechanism is not working efficiently. In order for a financing mechanism to be considered efficient, it should “...cause producers and consumers to internalize the right costs into their decisions” (Lee 1988, p.294). Efficiency requires a clear relationship between the cost imposed on society and the amount charged to those who benefit.

Efficiency gains are also a motivating objective behind the voluntary organization of parties for collective decision making, as occurs with LIDs, TIDs, and Transportation Corporations. In such cases, there is an expectation that collective action will result in an improvement of group welfare (Olson 1965). The expected efficiency improvement from collective action must account for the commitment of time and resources necessary for organizing the parties involved and reaching decisions.

The most efficient available financing mechanism for transportation infrastructure is widely agreed to involve direct user charges, such as gas taxes, vehicle registration fees, and parking charges. However, the efficiency (and yield) of these traditional charges has been deteriorating (Reno and Stowers 1995; TRB 2006). Efficient financing mechanisms that could potentially replace the gas tax are being explored (e.g., Road User Fee Task Force 2003), but full implementation of such alternatives, should they prove feasible, is still decades away. Thus, the financing mechanisms considered in this report can be generally characterized as "second best" approaches with respect to theoretically optimal efficiency. Nevertheless, these mechanisms offer a viable means of addressing contemporary transportation improvement needs. Their performance with respect to efficiency considerations thus merits further appraisal. Lastly, while there is not a great deal of optimism about the long-term viability of the gas tax, it nevertheless has fared very well with respect to efficiency principles (Brown 2001) since its 1919 introduction in Oregon, 13 years before the federal gas tax was adopted.

\subsection{COST AND EASE OF ADMINISTRATION}

The cost and ease of administration is a relevant consideration for a variety of reasons. If the cost of administration becomes too high, the net revenue remaining to fund transportation improvements may become inadequate. High administrative costs also detract from resource utilization efficiency. 
Lastly, high administrative costs are often an indication of challenges to effectively implementing a given financing mechanism.

Several of the financing mechanisms covered in this report are linked to systems that have very low administrative costs. The costs of administering the gas and property taxes, for example, are generally well below $5 \%$ of the revenue recovered. However, low administrative costs are sometimes achieved at the expense of other factors, such as tax evasion and equity. Evasion is a concern with the gas tax. FHWA (1992) estimated evasion rates of 3-7\% over all fuels and 15-25\% for diesel fuels subject to taxation. There are also concerns (although no published estimates) about tax avoidance with the increasing volume of alternative fuels in the market. Additional investments in auditing and enforcement activities would reduce fuel tax evasion, but would also add to overall administrative costs.

Equity, rather than evasion, is a concern with the property tax. The widespread adoption of mass statistical assessment techniques has driven down the cost of property tax administration. However, without regular systematic physical appraisal of properties, which adds to administrative costs, both horizontal and vertical equity of assessments deteriorates.

Trade-offs also occur between administrative costs and efficiency, particularly with respect to externalities. For example, the potential of gas tax for addressing important externalities is mixed. The ability of the gas tax to account for greenhouse gas externalities is quite good, considering that greenhouse gas emissions in transportation correspond closely to fuel consumption. Alternatively, the gas tax provides a poor means of addressing congestion externalities, which are particularly relevant in managing interchange area traffic operations. The most effective resolution of congestion externalities would require tolling technologies (still in development) whose administrative costs may be as great as $20 \%$ of the revenue recovered (NSTIFC 2009).

\subsection{TRANSPARENCY}

It is a generally accepted principle of public finance that a good revenue mechanism should be one that is transparent and which the general public (especially those being taxed) can easily understand. The gas tax, for example, is considered to be very transparent. The property tax is also considered to be transparent when assessments are based on market value. However, transparency is reduced when assessments and market values are uncoupled, as they have become in Oregon. Transparency is further diminished when property tax abatements are utilized to promote redevelopment or specific types of development, as is sometimes the case with urban renewal, affordable housing, and transit-oriented development programs.

As discussed in the previous chapter, traffic impact fees are most transparent when they are determined by a simple and straightforward method, such as a formula based on the ITE Trip Generation Manual. Transparency is reduced when the fees are waived for certain types of development, or modified to account for the timing, purpose, or chaining of trips. While the equity or efficiency of the fees may be improved, their transparency is reduced. 


\subsection{POLITICAL AND LEGAL FEASIBILITY}

Public acceptance and political feasibility are fundamentally important to the successful implementation of any financing mechanism. It is widely agreed among transportation finance analysts that a system of direct user charges would be the most desirable way to generate revenue for transportation improvements. Among the financing mechanisms considered in this report, the gas tax comes closest to directly charging transportation system users. For the most part, the gas tax has been effective at raising revenue for transportation infrastructure in a fairly equitable and efficient manner. However, it is no longer generally viewed as a politically feasible tool because voters and legislators have often rejected proposed increases. The property tax and its variants have encountered similar resistance.

Deen (2003) observes that the lack of divisibility of most transportation user costs (including taxes and user charges) and revenue allocation make it difficult to achieve both economic efficiency and widespread support. Vehicle registration fees, for example, are not divisible with respect to a vehicle's use, nor does the division of revenue from registration fees necessarily correspond to a vehicle's use or effect on the transportation system. Alternatively, the gas tax is divisible with respect to vehicle use, while division of the revenue recovered from the gas tax has gradually become less directly related to vehicle use and effect.

Both Deen (2003) and Greene (1998) observe that transportation measures directed toward few are more politically feasible than those directed toward many, even when the end result affects everyone. Thus, for example, fuel economy standards directed at vehicle manufacturers are preferred - even though their associated costs are fully capitalized in vehicle prices - over increases in the federal gas tax as a means to improve transportation energy efficiency. Similarly, a transportation impact fee levied on developers - even though it is fully capitalized in housing prices - is preferred over a surcharge or transaction tax levied against newly developed property as a means of funding transportation improvements. It is noteworthy that in both of these examples the preferred option also happens to be the less divisible alternative.

Legal feasibility is also important when considering alternative financing mechanisms. Since many of these tools have not been utilized extensively, their legal status, although established, may still be subject to challenge. Williams (2006) finds that ordinances, rules, and legislation governing the use of selected financing mechanisms vary from city to city and state to state.

Lastly, Forkenbrock (2006) encourages consideration of the extent to which a given financing mechanism supports other goals and initiatives of local government. In the context of this report, management of development within interchange areas is the most relevant local government initiative linked to the use of alternative financing mechanisms. While the monetary value of the synergistic benefits of coordinated management of development and financing of transportation improvements in interchange areas has not been explored, Burchell et al. (2002) estimated the transportation infrastructure costs under managed urban development to be about $12 \%$ lower than the costs associated with traditional development patterns. 


\subsection{FINANCING MECHANISMS EVALUATED AGAINST PUBLIC FINANCE CRITERIA}

The public finance criteria previously discussed can be used by local officials in assessing the suitability of the alternative financing mechanisms covered in this report. It is important to recognize that few, if any, financing mechanisms will completely satisfy all of the criteria in a given application. However, the criteria offer a useful framework for assessing the strengths and weaknesses of alternative mechanisms, and for better understanding of the tradeoffs that may arise. One of the biggest challenges in public finance is achieving an acceptable balance between equity and efficiency. The relative importance of each of the criteria will also likely vary across local jurisdictions and, within a jurisdiction, across applications. In short, no mechanism can be considered preferable independent of the context in which it is applied.

\subsubsection{Traffic Impact Fees/System Development Charges}

Yield: The ability of impact fees to generate revenue is dependent on the rate of development. Since the fees are ostensibly enacted in order to pay for infrastructure costs occasioned by new development, this is not necessarily a problem. But impact fees should not be thought of as a financing tool that will provide a consistent or stable yield. In principle it should be a fairly straightforward exercise to predict how much revenue impact fees will generate, although ease of prediction may vary with the methodology used to calculate fees. Overall, impact fees offer a potentially high revenue yield, although research indicates that the yield is routinely lower than the amount needed to fully offset the impact of development on transportation infrastructure.

Impact fees typically support pay-as-you-go financing of transportation improvements. However, when major improvements must be in place prior to development, impact fee revenue can provide a basis for debt financing. In this case it is important to ensure that the expected revenue yield from impact fees is sufficient to service the debt.

Equity: One of the main challenges with impact fees is ensuring equity between existing and new development. Research indicates that impact fees tend to favor existing development at the expense of future development. Existing property owners may see a windfall gain from increases in property values when infrastructure improvements are capitalized in real estate markets. There are also concerns that capitalization disproportionately impacts lower-income households by making housing less affordable, particularly for renters.

Efficiency: When impact fees are set below the full marginal cost of providing infrastructure to new development, efficiency losses occur. When capitalization of transportation improvements enhances the value of existing property, efficiency is also lost as a result of a breakdown in the correspondence between payment provided and benefits received. However, the efficiency losses associated with impact fees tend to be less the losses associated with other financing mechanisms.

Administrative Ease: Administering impact fees can become very complicated, requiring skilled staff and time to calculate the fees using complicated formulas. Generally, however, with fee schedules derived directly from trip generation estimates, administrative costs are low. Administration is also facilitated by coordination with the development review process. 
Transparency: The more straightforward the relationship between impact fees and trip generation, the more transparent is this financing mechanism. More complex methodologies for determining impact fees may reduce transparency but also improve efficiency and equity. Overall, impact fees are among the most transparent of the financing mechanisms covered in this report.

Political and Legal Feasibility: Although there have been challenges, the courts have generally upheld the right to charge impact fees, so long as they satisfy the rational nexus test. Residents support the idea that development should pay its own way. Although developers cannot be said to generally support impact fees, they tend to value the predictability and assurance of sufficient infrastructure capacity that follows payment. Impact fees also fare very well with respect to divisibility considerations.

\subsubsection{Fair Share Mitigation}

Yield: Since each case is negotiated separately, there is strong potential for assuring that revenue will be sufficient to cover the amount needed to provide the transportation improvement. The financial obligation (and risk) also falls on the developer rather than the government. However, it is difficult to predict how much will be finally agreed upon, and variances from case to case can arise based on the circumstances.

Equity: Generally, fair share mitigation can be considered equitable because the intent of the process is to hold a developer directly accountable for actions necessary to maintain the safety and function of transportation facilities. Inequities arise when earlier developers use up "spare capacity" and subsequent developers are held accountable. Improvements that are made may also benefit existing or subsequent development. In such cases, subsequent development can be held accountable through "zone of benefit” ordinances.

Efficiency: Fair share mitigation is efficient with respect to assuring correspondence between cost obligations and benefits received. The approach is also efficient in that it encourages development designs that minimize transportation impacts and the costs of mitigating impacts that occur. Distortions of efficiency may occur if the need for mitigation influences development location decisions. Also, efficiency losses occur because of the need to commit resources to negotiation, which is an administration intensive process. Resources dedicated to negotiation are somewhat fixed, indicating that this approach is most efficient when its use is limited to large scale developments or developments with potentially significant impacts on transportation facilities.

Administrative Ease: Fair share mitigation has been criticized for being difficult and costly to administer. Each case is negotiated separately and the effort/resources required to reach agreement are less predictable than for other financing mechanisms. A highly trained and experienced staff is required. Administrative costs are less burdensome when the threshold for employing this approach is set higher.

Transparency: The process itself is clearly defined and established, but since each case is negotiated individually, there is not a uniform, consistent outcome that can be expected. There is potential for manipulation occurring on either side of the negotiation. 
Political and Legal Feasibility: Fair share mitigation requirements of local governments vary from jurisdiction to jurisdiction.

\subsubsection{Tax Increment Financing}

Yield: The revenue yield from tax increment financing depends on the value dynamics of property contained in an urban renewal area (URA). Generally, the yield is substantial, but not necessarily stable or predictable. The yield is sensitive to the pace of development and appreciation of the tax base in the URA, which in turn is sensitive to the conditions of the wider local real estate market.

In Oregon, under property tax limitation Measure 50 (approved by voters in 1997), assessed values are allowed to grow a maximum of 3\% annually (Oregon Department of Revenue 2009).

Implementation of Measure 50 contributed to a widening gap between assessed values and market values (which were appreciating more rapidly) from the 1990s to the 2006 real estate market peak. Despite recent declines in real estate values, assessed values of properties remain substantially below their real market values in most of Oregon's local jurisdictions. Thus, while real market values are declining, assessed values, which represent the tax base, may not. Local jurisdictions have the ability to continue increasing assessed values $3 \%$ annually until assessed values reach market values. With respect to yield, as long as assessed values remain below market values, tax increment financing is capable of providing a larger and less volatile revenue stream than it otherwise would in a declining real estate market.

Equity: There are equity concerns with tax increment financing of transportation improvements. Generally, use of the tax increment is inconsistent with the philosophy that new development should be held fully accountable financially for its infrastructure impacts. Existing development carries a relatively greater burden with tax increment financing than with other financing mechanisms. Tax increments are also diverted from special districts within URAs so their revenue from URA properties is stagnant for the duration of the urban renewal program. The weight of these potential inequities will vary with the importance of proposed improvements to the current property owners

Efficiency: The most evident efficiency benefit of tax increment financing relates to the ability to undertake coordinated planning of transportation improvements and redevelopment within an urban renewal plan. Thus, in Portland, transit improvements have facilitated redevelopment at higher densities. With respect to interchanges, the IAMP process offers a similar opportunity to coordinate transportation and land use planning to enhance the efficiency of resources dedicated to transportation facilities.

Administrative Ease: Most local governments in Oregon have experience with tax increment financing. Compared to other financing mechanisms, the administrative component of urban renewal requires technically skilled staff and is procedure-laden. Jurisdictions lacking this expertise rely on consultants, which adds to administrative costs.

Transparency: Tax increment financing is often criticized for being too complicated for most people to understand. 
Political and Legal Feasibility: Some Oregon cities already have the maximum amount of land legally allowed to be designated as urban renewal areas. Tax increment financing is less likely to be opposed than new taxes, but there can be opposition related to the prospect that taxes will not keep pace for schools and other special districts. There are also concerns that urban renewal results in gentrification. Gentrification concerns have translated into community support for targeted funding of affordable housing in URAs. Although URAs must meet the definition of blight, the legal definition of this term in Oregon is broad and the designation of an area for the improvement of interchange and other transportation facilities would qualify.

\subsubsection{Value Capture}

Yield: The revenue yield of value capture financing depends on the mechanism(s) employed. The example of value capture most applicable to interchange area transportation improvements is the approach employed in Texas, which combines transportation impact fees with a modified form of tax increment financing. In this application, the tax increment is defined in relation to the projected growth of the interchange area tax base without transportation improvements, compared to the conventional application of tax increment financing, in which the tax base is frozen throughout the planning period.

The revenue yield from Texas-style value capture financing depends on the amount of development or redevelopment that occurs (or is promoted) in the interchange area over the planning period. Given the high level of regional accessibility associated with interchange area locations, prospects of future commercial development are likely to be better than those for other locations. Thus, in Oregon, the revenue potential would be strongly connected to the land use and zoning provisions of the IAMP.

Equity: As practiced in Texas, value capture financing is very equitable. New development is held responsible for its impacts on transportation infrastructure, and all development is subject to a tax on the incremental benefit that it receives from transportation infrastructure improvements. For new development, equity is sensitive to the structure of impact fees.

Efficiency: Within the IAMP process, value capture financing promotes efficiency in resource utilization, as well as efficiency in achieving a correspondence between tax liabilities and benefits received.

Administrative Ease: Administration characteristics of value capture financing are similar to those associated with traffic impact fees and tax increment financing.

Transparency: Transparency issues associated with the use of traffic impact fees and tax increment financing also apply to value capture financing.

Political and Legal Feasibility: Several local governments have enacted interchange impact fee ordinances for new development within IAMP areas. It is unclear whether the tax increment financing approach employed in Texas conforms to Oregon's urban renewal statutes and administrative rules. 


\subsubsection{Local Improvement Districts/Transportation Improvement Districts}

Yield: Revenue yield risks and concerns tend to be much lower with LIDs and TIDs. Revenue needs are determined as an outcome of the district formation and planning processes. Revenue can be raised from assessments based on any of a set property related characteristics.

Equity: Equity is sensitive to the method selected for assigning cost liability across district members. Equity is promoted when the method relates financing liability to expected benefit. Equity is also sensitive to the distribution of preferences across district members. Overall, the perception or expectation of equity is a necessary condition for organization of a district.

Efficiency: District formation is a signal of expected net efficiency gains from collective action.

Administrative Ease: Time, effort, and resources are needed to organize, maintain, and administer districts. An option to make payments over time and reasonable time frames to complete payment should be included in original agreements with property owners. Some risk is inherent in the decision on payment time frames: short time frames may create hardship for property owners while long time frames create risk that collections will be administered by staff unfamiliar with the district purpose and formation process.

Transparency: District functions are transparent to district members. District functions tend to be less transparent to the general public.

Political and Legal Feasibility: Local governments in Oregon generally have ordinances covering the formation of improvement districts. Given the organizational efforts and decision-making costs, improvement districts tend to include a limited number of members and district functions tend to focus on small-scale commitments. However, when potential gains from organization are substantial and apparent, and an equitable means of assigning liability can be achieved, improvement districts can be organized around larger projects (e.g., the Portland Streetcar).

\subsubsection{Transportation Concurrency}

Yield: When improvements are a necessary condition for development approval, the financing obligation falls on the developer. Thus, the revenue yield with transportation concurrency corresponds to the financing cost of the improvement. Financing risk also falls on the developer.

Equity: Earlier developers are allowed to freely use up existing capacity, while later developers are held accountable for adding new capacity. Developer costs of transportation improvements are capitalized in the prices, leases, and rents subsequently paid by occupants, reducing affordability.

Efficiency: Theoretically, concurrency influences developer decision-making to be more efficient by limiting development until infrastructure can be paid for. In practice however, concurrency requirements have often resulted in developers searching for spare capacity elsewhere. Location choices of developers subject to concurrency requirements may conflict with compact development objectives. 
Administrative Ease: In states where concurrency has been implemented, administration and management have been problematic. Systematic information needed to manage the program has been lacking.

Transparency: Transportation concurrency is fairly transparent to the parties subject to the requirements of the program, but may not be transparent to the general public.

Political and Legal Feasibility: Transportation concurrency requires enabling legislation for statewide implementation. In the pioneering state of Florida, transportation concurrency has been politically contentious. With the passage of Senate Bill 360 in the 2009 Legislative session, Florida eliminated transportation concurrency requirements within urban areas. Supporters of SB 360 contended that concurrency requirements were impeding urban infill development. Supporters also contended that the orientation of the program on capacity expansion was not effectively responding to travel from new development, given the existence of latent travel demand from existing development. Opponents of SB 360 contended that developers would no longer be held accountable for transportation infrastructure needs in the Transportation Concurrency Exemption Areas (where $70 \%$ of the state's population resides) identified in the legislation. Responsibility for financing transportation infrastructure improvements would thus shift to local governments and the state department of transportation.

\subsubsection{Transportation Corporations}

Yield: Given that transportation corporations tend to be organized in support of major transportation improvements, revenue needs tend to be large. Revenue yield characteristics depend on the choice of financing mechanism among numerous potential options. The sales tax offers the least stable or predictable choice, while a property tax-based option is among the most stable and predictable.

Equity: Equity depends on the financing mechanism employed, and successful implementation depends on voter approval. Thus the "median voter" issue may be relevant, depending on the distribution of costs and benefits.

Efficiency: The creation of a transportation corporation indicates an expectation of efficiency gains. Overall resource efficiency is offset by commitments required to form a transportation corporation and to support decision-making.

Administrative Ease: Transportation corporations are difficult to form, and reaching collective decisions can be time consuming and challenging. Administration of the financing mechanisms employed through transportation corporations is generally already in place, with low tax administration costs.

Transparency: The success of transportation corporations depends on extensive public involvement and voter support for financing initiatives. The more transparent the process, and the more evident the relationship of benefits and costs to voters, the greater is the likelihood of success.

Political and Legal Feasibility: Enabling legislation is required. 


\subsubsection{Local Option Transportation Taxes}

Yield: Revenue yield characteristics depend on the type of tax. Transportation utility fees generally provide a relatively stable (and potentially substantial) stream of revenue. Local option gas taxes can also generate a substantial revenue stream, but are more sensitive to the business cycle. Local option sales taxes are volatile with respect to the business cycle.

Equity: Except in the case of the gas tax, the general public is charged for the improvement, and financial liability may be only weakly related to benefits received. Also, some local option taxes tend to be more regressive (e.g., the sales tax). The median voter phenomenon can be potentially problematic.

Efficiency: Approval of local option measures indicates voter perception of an improvement in general welfare. Potential efficiency gains are negatively affected by 1 ) the resources required to define revenue needs and to promote needs to voters; and 2) the need to limit revenue to uses specifically approved by voters. The direct democracy appeal local option transportation taxes can be offset by challenges in coordinating voter approved and ongoing long term project planning and programming activities.

Administrative Ease: Most local option transportation taxes can be implemented within existing administrative structures. These supporting structures (e.g., property, sales, and gas tax administrations) are also among the lowest cost forms of tax administration. Compared to state gas taxes, evasion is less of a problem with local option gas taxes. However, jurisdictional price disparities arising from local option gas taxes could affect the pattern of gasoline sales.

Transparency: Given that the public is directly involved and affected by the outcome, local option transportation taxes tend to be very transparent.

Political and Legal Feasibility: Most local option transportation taxes are enabled by local government ordinances. Debt financing is usually subject to voter approval. HB 2001 prohibits the creation or amendment of local option gas taxes until January 2014.

\subsubsection{State Transportation Infrastructure Banks}

Yield: The Oregon Transportation Infrastructure Bank (OTIB) offers attractive debt financing to qualified borrowers. Yield characteristics relate to the source of revenue used to service the debt. In the examples presented in Section 3, transportation impact fees were secured for debt service. Impact fee revenue streams tend to be more volatile than the business cycle, and thus pose greater risk.

Equity: Equity implications depend on the mechanism chosen to service debt. When impact fees are used, cost responsibility falls on future development. The equity outcome thus depends on the extent to which the benefits of transportation improvements financed by OTIB also fall on future development. The opportunity cost of debt financing could also have equity consequences related to the commitment of future resources, thus limiting their availability to serve future needs. 
Efficiency: Below market financing improves overall resource efficiency for local governments compared to other debt financing mechanisms. Potential synergistic efficiency improvements also occur when OTIB financed transportation improvements are coordinated with commitments of ODOT funded improvements. Efficiency related to the correspondence of costs and benefits depends on the revenue source for debt service.

Administrative Ease: FHWA (2002) reported start-up difficulties experienced in some states. Initial challenges included gaining legislative authority and securing start-up capitalization. Following start-up, some states reported delays related to satisfying federal requirements for small projects (which added to overall project costs), as well as a lack of local interest. To date, the transition of the SIB program to a self-sustaining status (i.e., operating as true revolving loan enterprises) has been impaired by the small volume of initial loan activity.

Transparency: FHWA (2002) hypothesized that the slow start-up of the SIB program may have been a consequence of a lack of transparency to local governments, and recommended that more effort be devoted to marketing and outreach.

Political and Legal Feasibility: State enabling legislation has been passed and OTIB has been seeded with $\$ 50$ million of state funds to leverage federal matching funds. With its approval authority for both OTIB loans and IAMPs, the OTC is well positioned to facilitate coordination of planning, financing, and programming of interchange area transportation improvements.

\subsection{SUMMARY CONTEXTUAL ASSESSMENT}

As noted at the beginning of Section 4, the suitability of the financing mechanisms covered in this report is sensitive to the context in which transportation infrastructure improvements occur. With respect to interchange areas, the context can generally be distinguished by differences in prevailing and projected traffic and development conditions. Previous analysis (Strathman et al. 2005) identified a typology of interchanges in Oregon covering three distinct traffic and development contexts. The first context included rural interchanges. The performance of these facilities generally conforms to OHP interchange mobility standards, and the amount of nearby development activity is fairly limited. When improvements to existing interchanges or new interchanges are planned in this setting, the associated IAMP tends to focus on ensuring the maintenance of existing zoning (often exclusive farm use) and the preservation of access control. The Rickreall IAMP (Polk County and ODOT 2005) is an example that reflects this context.

The second context includes interchanges located at the fringe of urban areas, usually just inside an urban growth boundary. The rate of development in the interchange area has been fairly rapid, and the area is not yet fully built out. The performance of the interchange is approaching its design limit, and the need for a major interchange improvement is apparent. An IAMP prepared under these circumstances must reconcile a number of planning and financing issues. An overarching issue is the need to ensure that the OHP interchange mobility standard can be met over the design life of the improvement. This may involve substantial amendments to the local TSP, preparation of an interchange area access management plan, establishment of a future trip budget for the interchange area, and identification of trip reduction actions. An IAMP might also identify financing responsibilities for interchange area transportation improvements identified in the TSP. 
In instances where it is apparent that interchange improvements are directly benefiting interchange area development, an IAMP would include the negotiated division of financing responsibility for interchange improvements between local government and ODOT. The Woodburn IAMP (ODOT $2006 b$ ) is an example that reflects this context.

The third context includes interchanges located in developed urban areas. The existing performance of these interchanges is generally near or above the OHP mobility standard. The area in the vicinity of the interchange is generally fully built out. However, local governments may seek to promote higher density development in the interchange area, as reflected in comprehensive plan amendments. There may not be a motivation to prepare an IAMP and improve the affected interchange. Nevertheless, under the Transportation Planning Rule, a comprehensive plan amendment within the interchange area would trigger a review of the projected traffic effects on the performance of the interchange. Should the projected effects of the plan amendment on interchange performance prove significant, mitigation actions must be identified along with either committed funding or a confirmation that a future commitment of funding is reasonably likely.

A rationalization of the division of financing responsibilities for interchange improvements between local governments and ODOT can be readily established in two of the three contexts described above. First, in the case of rural interchanges, IAMPs generally seek to limit development in interchange areas. Rural interchange improvements are thus generally intended to benefit statewide and regional traffic. This intent is reflected in ODOT's usual practice of bearing full financing responsibility for rural interchange improvements. Second, in the case of urban fringe interchanges, IAMPs generally seek to address the infrastructure needs of nearby existing and expected development. Negotiation over the division of financing responsibility for interchange improvements between ODOT and local government rests on the breakdown of anticipated future benefits to statewide and regional traffic, for which ODOT should bear financing responsibility, and to traffic with interchange area destinations, for which local government should bear financing responsibility. Also relevant to the negotiation is the extent to which the dynamics of prior interchange area development contributed to the premature obsolescence of the existing interchange.

The rationale for a division of financing responsibility in the case of urban core interchanges in the context of the Transportation Planning Rule is less certain. For example, in previous work (Strathman et al. 2005), statistical analysis identified a significant relationship between interchange area comprehensive plan amendments and subsequent increases in traffic volumes on rural and urban fringe interchanges. However, comprehensive plan amendments in urban core interchange areas were estimated to have no significant subsequent effect on interchange traffic volumes. There are several possible explanations for this latter outcome. First, the impedance of an urban core interchange operating at capacity may act to divert trips generated from new development to other routes on the local transportation system, or to suppress trip generation. Second, the existence of travel mode options in urban core areas raises the possibility that trip generation from new development may be disproportionately accommodated by non-auto modes. Additional research is needed to gain a better understanding of the traffic consequences of development in this setting.

Given the findings of prior research, the most relevant context for considering the potential application of alternative financing mechanisms would be in connection with the preparation of 
IAMPs for urban fringe interchange improvements. Infrastructure improvements to be financed in this context would typically include changes in the road network within the interchange area, as well as a local contribution to an interchange facility improvement. A second context for considering alternative financing mechanisms would be in connection with the TPR review of comprehensive plan amendments in interchange areas. In this context, financing of a broader range of transportation system improvements may occur, depending on the significance of the traffic impacts of projected development. Considering the uncertainty associated with the extent and nature of improvements that may occur as an outcome of the TPR review, the discussion below will focus mainly on the context involving urban fringe interchanges.

An assessment of the general suitability of the alternative financing mechanisms in the urban fringe interchange context is presented in Table 4.1.

Table 4.1: General Contextual Suitability of Alternative Financing Mechanisms

\begin{tabular}{|c|c|c|}
\hline Financing Mechanism & $\begin{array}{l}\text { General Suitability } \\
\text { (Low / Moderate / } \\
\text { High) }\end{array}$ & Suitability Considerations \\
\hline $\begin{array}{l}\text { Traffic Impact Fees / } \\
\text { System Development } \\
\text { Charges }\end{array}$ & Moderate/High & $\begin{array}{l}\text { Most suitable when it is determined that the need for } \\
\text { improvements is occasioned by projected future } \\
\text { development, and when it is determined that } \\
\text { existing development has not contributed to } \\
\text { premature obsolescence of the existing interchange. } \\
\text { When these conditions are not met, impact fees can } \\
\text { be supplemented with financing mechanisms linked } \\
\text { to existing development (e.g., TIDs, Value Capture). }\end{array}$ \\
\hline Fair Share Mitigation & Low/Moderate & $\begin{array}{l}\text { Most suitable when employed to minimize the } \\
\text { traffic and safety impacts of large developments, } \\
\text { and to ensure capacity preservation and maintenance } \\
\text { of IAMP trip budgets. }\end{array}$ \\
\hline $\begin{array}{l}\text { Tax Increment } \\
\text { Financing }\end{array}$ & Low/Moderate & $\begin{array}{l}\text { Most suitable when applied to multimodal } \\
\text { transportation system improvements in urban core } \\
\text { interchange areas, in connection with local } \\
\text { redevelopment. Low suitability for urban fringe } \\
\text { applications due to equity issues, except where } \\
\text { existing development is responsible for premature } \\
\text { obsolescence of a transportation facility. }\end{array}$ \\
\hline Value Capture & Moderate/High & $\begin{array}{l}\text { (As practiced in Texas) most suitable when the } \\
\text { benefits of interchange and interchange area } \\
\text { improvements are distributed over existing and } \\
\text { projected development. Generally more complex } \\
\text { and costly to administer, and less transparent, when } \\
\text { structured to achieve equity and efficiency. } \\
\text { Authorizing legislation in Oregon would be needed. }\end{array}$ \\
\hline
\end{tabular}




\begin{tabular}{|c|c|c|}
\hline Financing Mechanism & $\begin{array}{c}\text { General Suitability } \\
\text { (Low / Moderate / } \\
\text { High) }\end{array}$ & $\begin{array}{c}\text { Suitability Considerations } \\
\end{array}$ \\
\hline $\begin{array}{l}\text { Transportation } \\
\text { Improvement Districts / } \\
\text { Transportation } \\
\text { Development Districts }\end{array}$ & Moderate & $\begin{array}{l}\text { Most suitable when the benefits of interchange and } \\
\text { interchange area improvements fall on existing } \\
\text { development, and the potential for future } \\
\text { development is limited. May be more suitable for } \\
\text { new interchanges than improvements to existing } \\
\text { interchanges. More challenging to organize and } \\
\text { administer, but internal commitments ensure the } \\
\text { predictability of needed revenue. }\end{array}$ \\
\hline $\begin{array}{l}\text { Transportation } \\
\text { Concurrency }\end{array}$ & Low & $\begin{array}{l}\text { Promotes efficiency and equity in principle, but in } \\
\text { practice development tends to be attracted to } \\
\text { locations with available transportation capacity. } \\
\text { Promotes incrementalism over long range system } \\
\text { planning. Not directly applicable in Oregon. }\end{array}$ \\
\hline $\begin{array}{l}\text { Transportation } \\
\text { Corporations }\end{array}$ & Moderate & $\begin{array}{l}\text { Most suitable when multiple jurisdictions and } \\
\text { stakeholders are parties to or affected by an IAMP. } \\
\text { Revenue yield for improvements depends on voter } \\
\text { approval and voluntary contributions. Generally } \\
\text { more suitable for new interchanges where benefits } \\
\text { spill beyond the immediate interchange area, such as } \\
\text { near rural and exurban (i.e., beyond the urban } \\
\text { fringe) communities. Authorizing legislation in } \\
\text { Oregon would be needed. }\end{array}$ \\
\hline $\begin{array}{l}\text { Local Option } \\
\text { Transportation Taxes } \\
\text { (LOTTs) }\end{array}$ & Low/Moderate & $\begin{array}{l}\text { Most suitable when the benefits from the } \\
\text { interchange and interchange area improvements } \\
\text { correspond to the boundaries of the jurisdiction } \\
\text { voting on the financing measure. This may occur } \\
\text { when improvements are planned for multiple } \\
\text { interchanges in a metropolitan area, or when a new } \\
\text { rural interchange results in a community-wide } \\
\text { benefit. }\end{array}$ \\
\hline $\begin{array}{l}\text { State Infrastructure } \\
\text { Banks }\end{array}$ & Moderate/High & $\begin{array}{l}\text { When debt financing is necessary, SIBs offer } \\
\text { attractive below-market rates. Loan term also } \\
\text { coincides with the design life of improvements. } \\
\text { Efficiency, equity, and transparency depend on } \\
\text { source(s) of revenue used to service debt. } \\
\text { Administration is relatively easy at low cost. Debt } \\
\text { service "locks up" future revenue, limiting } \\
\text { flexibility later on. }\end{array}$ \\
\hline
\end{tabular}

As is evident in the table's characterizations, the general suitability of each financing mechanism is sensitive to the distribution of improvement-related benefits in several respects. First, where the benefits fall on future development, the suitability of impact fee mechanisms is enhanced. Alternatively, where the benefits fall on existing development, the suitability of tax increment financing and transportation improvement districts is enhanced. And in instances where the benefits of interchange improvements are shared between existing and future development, the suitability of value capture mechanisms is enhanced. 
Second, where the benefits from interchange improvements spill beyond the interchange area, the suitability of mechanisms such as transportation corporations and local option transportation taxes is enhanced.

Third, characterization of the suitability of several debt financing mechanisms, including state infrastructure banks and selected local option transportation taxes depends on the source of the revenues servicing the debt. Thus, when an SIB loan is secured against future transportation impact fee revenues, it suitability is enhanced when the improvement financed by the loan primarily benefits future development.

Lastly, several of the mechanisms listed in the table are characterized as having relatively low suitability across the defined interchange improvement contexts. With respect to transportation concurrency, this assessment reflect the fact that transportation concurrency is not practiced in Oregon, as well as an expectation of its limited prospects for future adoption. With respect to fair share mitigation, the assessment reflects the expectation that this practice will typically supplement a chosen financing mechanism. 


\subsection{CASE STUDIES}

This chapter presents two case studies of the use of alternative financing mechanisms in funding transportation improvements in interchange areas. The first case study focuses on the I-5 Woodburn Interchange, in which the adoption of an IAMP in 2006 represented the culmination of more than 25 years of cooperative planning and management of development between ODOT and the City of Woodburn. It is likely that no other interchange on the state highway system has witnessed a comparable legacy of sustained coordination of effort directed toward preserving a facility's function, planning for a facility's redesign and construction, and ensuring a facility's future performance over its designed life. The second case study focuses on the I-5 Fern Valley Interchange, located in the City of Phoenix (at the southern edge of the Medford metropolitan area). The IAMP for this interchange is presently in draft form and has not yet been adopted by the OTC.

Although the planning legacy of the Fern Valley Interchange is not as extensive as Woodburn's, the development, planning and financing challenges faced by both share several important features. First, both interchanges are located at the fringe of a rapidly developing jurisdiction, and planning for interchange improvements has involved treatment of expected future development. Second, both plans for interchange and interchange area improvements involve alternative financing mechanisms. Third, the IAMPs for both facilities address the division of financing responsibility between existing and future development in the interchange area. Lastly, a division of financing responsibility for both interchange improvements also exists between the municipality and ODOT.

\subsection{WOODBURN INTERCHANGE CASE STUDY}

The Woodburn interchange is located at I-5 and OR-214 at the western fringe of Woodburn. The original interchange was built in the 1960s. It was redesigned to its current configuration in 1970 and rebuilt in 1975. ODOT provided funding for the 1975 reconstruction. In the late 1980s, ODOT programmed anticipated funds to further improve the interchange, but subsequently cancelled planning and funding after a proposed gas tax increase failed in the 1993 legislative session.

From 1975 to the present there have been substantial changes related to development in the interchange area, as well as in the planning, funding, and mitigation efforts involving ODOT and the City of Woodburn. Figure 5.1 identifies major relevant milestones over this period pertaining to improvements to the interchange and its intersecting state highways, major development in the interchange area involving significant mitigation, adoption and updates of Woodburn's comprehensive plan and transportation system plan, interchange area management plan, and financing of interchange improvements. These subjects are discussed in turn below. 


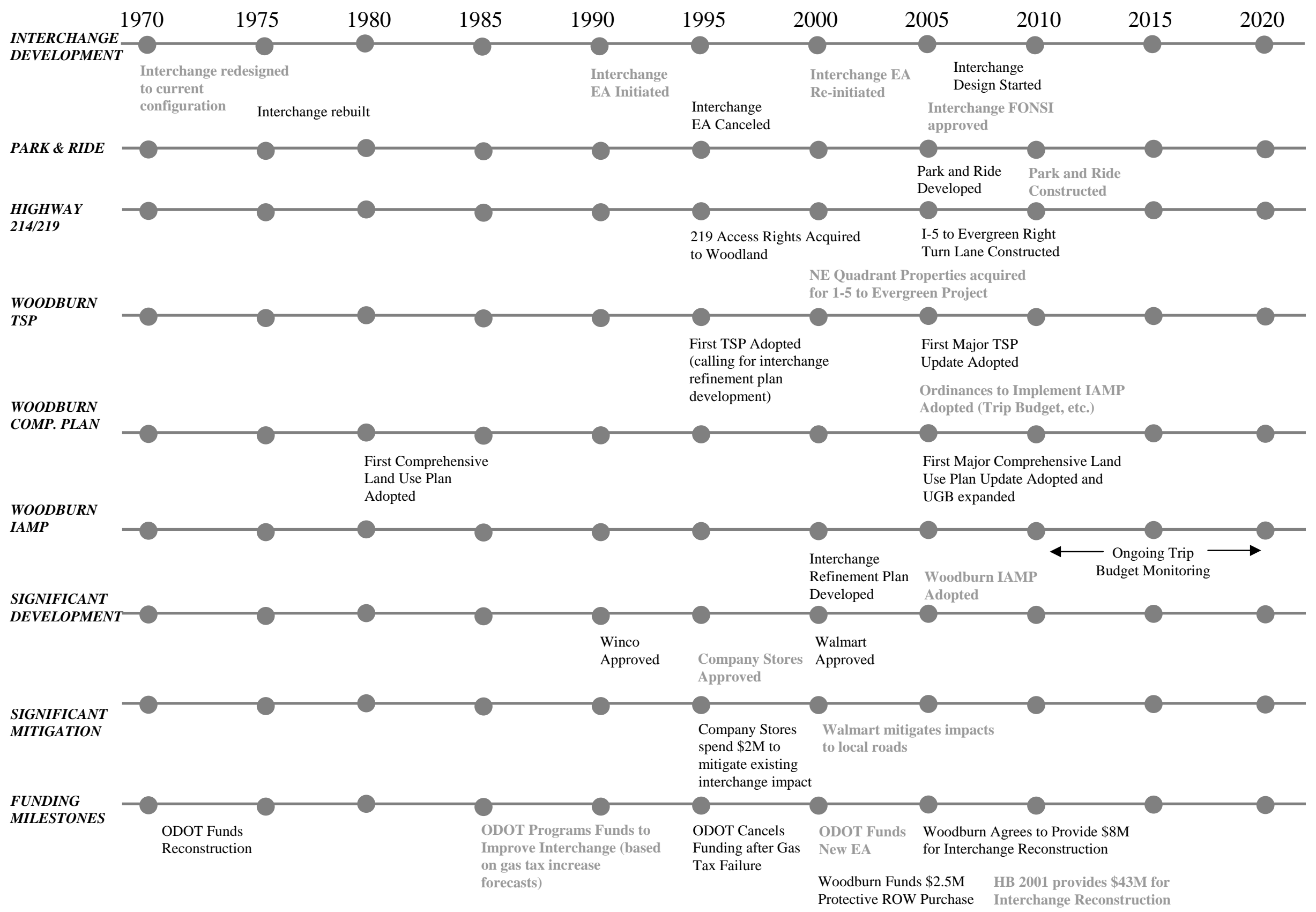

Figure 5.1: Woodburn Interchange: Significant Planning, Funding, and Development Milestones 
Woodburn's first comprehensive land use plan was adopted in 1981. By establishing its urban growth boundary west of the interchange, the city signaled that development would be encouraged in the interchange area. ODOT expressed concern in the plan acknowledgement process that the interchange would be unable to accommodate the traffic generated from nearby development identified in the comprehensive plan. Woodburn has experienced higher than anticipated population growth and development since its comprehensive plan was first adopted. Its 2000 population reached the total forecasted for 2012, and by 2005 it had tripled from what it was in the 1960s. In 2005 Woodburn's comprehensive plan was updated, further expanding its urban growth boundary.

Commercial development in the interchange area has been fairly extensive over the past 30 years. In the 1990s, three major commercial developments occurred, and significant mitigation actions were undertaken as conditions of their approval. The first major development, a Winco regional distribution center located in the southwest quadrant of the interchange area, involved mitigation that included upgrading of Woodland Road, improvements at the intersection of Woodland and OR 219, and the addition of a travel lane on OR 219 from the intersection to the southbound interchange on ramp. The second major development, the Woodburn Company Stores located in the northwest quadrant of the interchange area, involved mitigation that resulted in the reconstruction of a frontage road (Arney Rd.) serving Company Stores property and, potentially, future development of other frontage properties. In this case, the City of Woodburn passed an ordinance authorizing the Company Stores to recover a share of its frontage road improvement costs from future frontage property development. To date, the Company Stores have not exercised this authority. The Company Stores also contributed to signalization, ramp, and signage improvements.

In coordination with mitigation activities associated with the Winco and Woodburn Company Stores developments, ODOT also acquired the access rights of properties fronting OR 219 between the interchange and the Woodland Road intersection. This action ensured long run compliance with the Division 51 interchange area access standard west of the interchange.

The third major development, a Walmart Supercenter located in the southeast quadrant of the interchange area, involved mitigation that included improvements to both Evergreen Road and Stacy Allison Way, both of which provide access to the property. Improvements were also made to the intersection of Evergreen Road and OR 214.

Although commercial activity exists in the northeast quadrant of the interchange area, no major commercial development has been undertaken as in the other quadrants. Here, property fronting OR 214 between Evergreen Road and the interchange’s northbound onramp has been acquired to develop a park and ride facility serving the Woodburn Transit Division and, potentially, shuttle services running along the I-5 corridor between Portland and Salem (ODOT 2009a). Part of the property will also be dedicated to construction of another travel lane on OR 214 between Evergreen Road and the northbound onramp.

Although planning and programming of interchange improvements was interrupted in the early 1990s, Woodburn's first TSP, adopted in 1996, called for the development of an interchange refinement plan. Subsequently, the City and ODOT agreed to proceed by coordinating an update of the TSP and comprehensive plan with the preparation of an IAMP. The comprehensive plan update was approved in 2005, and the IAMP and the TSP update were adopted in 2006. Coincidentally, 
the environmental assessment of interchange alternatives was begun in 1999 and completed in 2005. In 2008 a finding of no significant impact (FONSI) was made and the design phase of the project was thereafter initiated. Construction is scheduled to begin no earlier than 2013.

The approved interchange alternative will replace the existing diamond interchange with a cloverleaf design. The design will improve safety conditions and traffic flow, and will allow the interchange to meet the OHP mobility standards over its lifetime. The improvement will also provide sufficient capacity to serve the growth assumptions outlined in the 2005 comprehensive plan update. Long-term assurance of these outcomes is fortified by the inclusion of a trip budget in the IAMP that sets traffic generation limits for future development.

The approved interchange plan includes the following features (ODOT 2009b):

- Reconstructing the interchange to a partial cloverleaf

- Widening the existing over crossing structure (bridge) to the north

- Raising the profile of the bridge approaches in order to improve sight lines

- Widening OR 214 and 219 equally or north of the existing centerline, depending on the segment

- New 6-foot sidewalks with an additional 6-foot-wide landscaped buffer between the sidewalk and the curb

- A new bicycle lane in each direction along OR 214 and 219

- A raised median to control turning movements

- Modifying access for city streets at Oregon Way, Evergreen Road and Lawson Avenue.

The cost estimate for the interchange project is $\$ 70$ million. Recognizing that development in interchange area partially led to the functional deterioration of the interchange, Woodburn has committed to contributing $\$ 8$ million toward the total cost (Intergovernmental Agreement No. 23240). These funds will be drawn from traffic impact fees that have been collected citywide, as well as from revenues generated by a new interchange development charge (IDC) passed by the City in April 2008 (Section 2 of Ord. No. 2438). The IDC covers all new development that occurs within a designated interchange development area. Redevelopment is also subject to the IDC if it is expected to generate additional traffic. The IDC must be paid in addition to the general system development charge required of all new development in Woodburn.

ODOT has also made an initial commitment of $\$ 8$ million toward the interchange project. Woodburn has already used $\$ 2.5$ million of its $\$ 8$ million commitment in a protective purchase of property in the future right of way. House Bill 2001, passed by in the 2009 legislative session, identified the Woodburn interchange project among those that will receive funding from the state. HB 2001 dedicates \$43 million to the Woodburn project. At present, \$10 million of the total project cost is yet to be identified.

This case study provides a fairly complex and extended illustration of the use of several financing mechanisms, as well as highlighting several procedural considerations involving state-local 
collaborative planning. The most noteworthy finance-related features of this case in the context of issues covered in this report are the following:

- Ongoing reliance on fair share mitigation of the traffic impacts of major development to preserve the function and safety of the interchange and other state and local transportation facilities in the interchange area.

- Recognition that mitigation actions may benefit future development, with a formal allowance for the recovery of those benefits should future development occur.

- Purchase of access rights to preserve the function and safety of state facilities in the interchange area.

- Division of financing responsibility between a local jurisdiction and ODOT corresponding to an acknowledged division of benefits between interchange area and local travel, and statewide and regional travel.

- Division of local financing responsibility between existing and future development in the interchange area.

- Recognition of community level spillover benefits beyond the interchange area from interchange improvement.

Procedurally, the timeline extending from the date when the need for interchange improvement was first acknowledged to the date when reconstruction is scheduled to begin has been much longer than typical. State funding uncertainties in the 1990s clearly contributed to lengthening the timeframe. By itself, a longer timeframe is not desirable, although in this case it did lead to several positive outcomes. First, the funding uncertainty in the 1990s resulted in a joint resolve by ODOT and Woodburn to preserve the capacity of the existing interchange as long as possible. Thus, through both fair share mitigation and purchase of access rights, ODOT and Woodburn worked together to effectively demonstrate the value of these tools. Second, the decision to coordinate updates of Woodburn's TSP and comprehensive plans with the IAMP helped to ensure that plans for local and state transportation facilities and plans for development were consistent, reinforcing, and achievable. Third, as indicated above, the division of financing responsibility faced complex trade-

offs at the local level, and between local and state government. The outcome realized was a product of discussions and decision making that evolved over an approximate 10 year period. Thus the Woodburn Interchange experience offers a potentially useful case for consideration in other interchange improvement situations, and will likely facilitate more timely reconciliation of financing issues in the future.

\subsection{FERN VALLEY INTERCHANGE CASE STUDY}

The I-5 Fern Valley Interchange is located 24 miles north of the California border at the western edge of the city of Phoenix. The interchange has not been updated since its construction in the 1960s. It faces increasing congestion and safety problems as a result of growth in the Phoenix and Southeast Medford areas. Congestion is also a concern on Fern Valley Road, which crosses over I5 at the interchange. In addition, the intersection of Fern Valley Road and OR 99 (about 1,800 feet west of the interchange) and the intersection of Fern Valley Road and North Phoenix Road (about 
1,000 feet east of the interchange) are expected to need improvement to accommodate projected traffic growth. A draft IAMP has been prepared for the interchange and other transportation improvements.

Commercial development is most concentrated in the southeast and northwest quadrants of the interchange area. Major businesses include a retail outlet mall in the northwest quadrant and a TravelCenters of America Truck Stop in the southeast. A Home Depot is located in the northeast quadrant.

Phoenix's existing urban growth boundary limits further development in the northeast quadrant of the interchange area. However, it is expected that the City will amend the UGB outward and update its comprehensive plan, rezoning this area to commercial use. In addition, the draft Greater Bear Creek Valley Regional Plan prepared by the Rogue Valley Council of Governments has identified a substantial part of the quadrant, now zoned exclusive farm use, as urban reserves to accommodate future development of Medford. Currently, with a tax base per capita about 25\% below that of Medford, Phoenix is under fiscal pressure in its efforts to provide services to city residents. Thus, the City has expressed an intention to generally promote commercial development in the future, which will affect traffic and mobility in the interchange area.

The draft IAMP addresses the disparity between existing plans and locally and regionally-expressed future intentions by projecting traffic impacts on interchange area facilities under two scenarios. The first scenario reflects traffic impacts associated with future build-out under the zoning contained in the existing comprehensive plan, while the second scenario reflects impacts related to build-out under anticipated UGB and comprehensive plan amendments. In each case, the projections are related to the relevant OHP mobility standards for interchanges, intersections and other facilities. Transportation infrastructure improvements in the interchange area are then designed such that the OHP mobility standards are not exceeded under the second build-out scenario.

The draft IAMP establishes a peak hour trip budget to be adopted by the City of Phoenix for the interchange management area to ensure that future traffic impacts do not exceed OHP mobility standards. A tax lot level parcel budget also establishes the number of peak hour trips that may be generated by a parcel without City approval. The difference between the total trip budget and the sum of the parcel budgets, referred to as a "trip bank," defines a net balance of new trips the City would authorize over a 20-year planning period. The draft IAMP states that City approval of new trips beyond its trip bank balance would be conditioned by providing additional capacity at the OR 99-Fern Valley Road intersection, or by actions that would divert traffic away from this intersection.

Lastly, the draft IAMP recognizes that future mobility in the interchange area will also be influenced by through traffic (especially on OR 99) and by new development occurring beyond the City's immediate jurisdiction. Thus, it adopts by reference the existing UGBs delineated by both Phoenix and Medford, along with existing zoning and land use designations contained in the Jackson County Comprehensive Plan. The draft IAMP states that future amendments to the County's comprehensive plan will be evaluated with respect to corresponding effects on the function or performance of the interchange. In cases where a plan amendment is considered to be 
incompatible with the IAMP, ODOT would first work with Jackson County to reach an agreement before seeking review by the Oregon Land Use Board of Appeals.

The Fern Valley Interchange project has a programmed cost of \$70 million. To date, \$2.45 million has been expended to relocate two local street intersections away from the interchange. Future planned construction, scheduled to begin no earlier than 2012, includes the following:

- Construction of a new crossing-diamond interchange

- Widening of Fern Valley Road to two lanes in each direction between OR 99 and N. Phoenix Road (coinciding with a transfer of jurisdiction from the City of Phoenix to ODOT and classification of the segment as a District Highway). Widening would also include pedestrian and bicycling facilities.

- Construction of a new bridge on Fern Valley Road where it crosses over Bear Creek

- Improvements at the intersections of Fern Valley Road with OR 99 and N. Phoenix Road.

- $\quad$ Realignment and widening of N. Phoenix Road

Funding sources for the project include \$25 million dedicated in House Bill 2001 and a commitment of $\$ 6.8$ million from the City of Phoenix. Related to its funding commitment, the City has adopted an interchange development charge (IDC) ordinance for all new development and redevelopment within the city, unless exempted. According to the city of Phoenix municipal code, "(t)he purpose of the IDC is to create a fund to pay for the installation, construction, extension and expansion of certain transportation capital improvements and to impose an equitable share of the cost of these capital improvements on the developments that create the need for, or increase the demand on, them" (3.20.050). The IDC is separate from and in addition to transportation system development charges previously authorized by the city. The fee is due at the time development "imposes new or increased demand upon these public improvements or upon issuance of a building permit or business license, whichever comes first” (3.20.050). IDC revenues cannot be used to construct administrative offices or for maintenance of capital improvements.

Although Phoenix, like Woodburn, introduced an IDC to finance its funding contribution to the Fern Valley interchange area improvements, there are notable financing and procedural differences between the two cases. First, in the case of Fern Valley, there is an expectation of relatively stronger interchange area development over the planning horizon, and the Phoenix IDC is thus intended to direct the financing liability more squarely on future development.

Second, in preparing the IAMP for the Fern Valley interchange, it was apparent that the Phoenix UGB and comprehensive plan would be amended to promote future growth, and it thus was necessary to take these intentions into account. This also introduced an element of uncertainty in the planning process that was not present in the Woodburn case, where preparation of the IAMP was coordinated with the city's TSP and comprehensive plan updates.

Third, in the case of the Fern Valley interchange, it was necessary to address potentially substantial future development impacts originating outside the interchange management area and the City of Phoenix's jurisdiction. Thus, even though the IAMP was a collaborative effort between ODOT and 
the City of Phoenix, it was also necessary to develop and include measures linking the Fern Valley IAMP to other comprehensive plans in the region. 


\subsection{CONCLUSION}

This report has examined the use of alternative local financing mechanisms for interchange and interchange area infrastructure improvements. The financing mechanisms covered include transportation impact fees, tax increment financing, value capture financing, local improvement districts, transportation corporations, state infrastructure banks, local option transportation taxes, fair share mitigation, and transportation concurrency.

Focusing the report on interchange applications reflects the policy and planning attention that have been directed toward these facilities, resulting in growing collaboration between ODOT and local governments. For example, Interchange Area Management Plans must be completed and approved by local governments and the Oregon Transportation Commission prior to construction or significant modification of interchanges. These plans must identify state and local transportation system improvements necessary to ensure that interchange facilities perform as designed over their design life.

Secondly, the Transportation Planning Rule identifies ODOT's responsibility to review proposed urban growth boundaries and comprehensive plan amendments in the vicinity of interchanges. When such land use changes would result in a significant increase in interchange traffic volume, the Transportation Planning Rule requires local governments to identify improvements with committed funding to mitigate effects on interchange performance.

Lastly, common to both Interchange Area Management Plans and Transportation Planning Rule review, the Oregon Highway Plan designates mobility standards for all state facilities, including interchanges. These standards establish the basis for which facility and system plans are prepared, and against which land use changes are evaluated.

Financing mechanisms are first reviewed with respect to their general application to funding transportation improvements. This review provides a literature-based appraisal of their advantages and disadvantages, and, where applicable, examples of their use in Oregon. Subsequently, the focus is narrowed to assessing the financing mechanisms' suitability for funding interchange-related improvements. This assessment is based on established public finance criteria, including revenue yield and stability, efficiency and equity, cost and ease of administration, transparency, and political and legal feasibility. The assessment is also structured to account for differences in locational and land use contexts that research and past planning experience indicate are relevant to financing decisions on interchange improvements.

The report concludes with a presentation of two case studies that illustrate the approaches taken by ODOT and local governments in planning for and financing interchange improvements. Both case studies cover the preparation and content of Interchange Area Management Plans. However, the planning and development contexts involved in these efforts are substantively different. 
The principal conclusion of this report is that choices of financing mechanisms need to be sensitive to location and development context-specific conditions. Thus, while some alternatives exhibit characteristics that generally favor their use in given circumstances, none of the financing mechanisms predominates over the others, even considering the relatively narrow focus of the report on interchange area applications. Also, as one of the case studies shows, conditions may lead to the use of multiple mechanisms. In this respect, the report is intended to serve as a handbook for planners and decision makers, explaining how financing mechanisms work, describing how they have been applied, and presenting issues to be considered in making financing decisions. 


\subsection{REFERENCES}

AECOM Consult. 2007. Evaluation of Impact Fees and Value Capture Techniques. Briefing paper prepared for the National Surface Transportation Policy and Revenue Study Commission, Washington, DC.

Altshuler, A.A., Gomez-Ibanez, J.A., and A.M. Howitt. 1993. Regulation for Revenue: The Political Economy of Land Use Exactions. Washington, DC: The Brookings Institution.

Batt, H.W. 2001. Value capture as a policy tool in transportation economics. American Journal of Economics and Sociology, 60, 195-228.

Bauman, G. and W.H. Ethier. 1987. Development exactions and impact fees: A survey of American practices. Law and Contemporary Problems, 50, 51-68.

Belson, K. 2009. Stadium boom deepens municipal woes. The New York Times. December 24.

Brown, J. 2001. Reconsider the gas tax: Paying for what you get. Access, 19, 10-15.

Bowles, L.K. and A.C. Nelson. 2008. Impact Fees and Housing Affordability: A Guidebook for Practitioners. Prepared for the U.S. Department of Housing and Urban Development, Washington, DC.

Burchell, R.W., Lowenstein, G., Dolphin, W.R., Galley, C.C., Downs, A., Seskin, S., Still, K.G. and T. Moore. 2002. TCRP Report 74: Costs of Sprawl - 2000. Washington, DC: Transit Cooperative Research Program, Transportation Research Board of the National Academies,.

Butorac, M. and J. Wen. 2004. NCHRP Synthesis 332: Access Management on Crossroads in the Vicinity of Interchanges. Washington, DC: National Cooperative Highway Research Program, Transportation Research Board of the National Academies.

Callies, D.L. and W.S. Richardson. 2000. Street and Road Exactions After Dolan. Paper presented at the American Planning Association Annual Conference, New York.

Carrion, C. and L.W. Libby. 2001. Development Impact Fees: A Primer. Ohio State University, Department of Agricultural, Environmental, and Development Economics. Working Paper: AEDE-WP-0022-01.

Center for Urban Transportation Research (CUTR). 2007. Transportation Concurrency: Best Practices Guide. Center for Urban Transportation Research, University of South Florida. Accessed at http://www.cutr.usf.edu/pub/files/DCA_TCBP\%20Guide.pdf, March 2009. 
Cervero, R, Murphy, S., Ferrell, C., Goguts, N., Tsai, Y., Arrington, G., Boroski, J., SmithHeimer, J., Golem, R. Peninger, P., Nakajima, E., Chui, E., Dunphy, R., Meyers, M., McKay, S. and N. Witenstein. 2004. TRCP Report 102: Transit Oriented Development in the United States: Experiences, Challenges and Prospects. Washington, DC: Transit Cooperative Research Program, Transportation Research Board of the National Academies.

Chapman, J.I. 2008. The fiscalization of land use: The increasing role of innovative revenue raising instruments to finance public infrastructure. Public Works Management and Policy, Vol. 12, 551-567.

City Club of Portland. 2005. Portland Development Commission: Governance, Structure and Process. Portland, OR: author.

City of Eugene, Oregon. 2004. 2004 Oregon System Development Charge Survey. Public Works, Engineering. Accessed at http://www.eugeneor.gov/portal/server.pt/gateway/PTARGS_0_2_174462_0_0_18/EugComparison04Nov.pdf, March 2009.

City of Ontario. 2006. Resolution 2006-129: A Resolution Establishing Fees and Charges for System Development Fees for the City of Ontario.

Cortright, B. 2008. TPR, Rezoning and Traffic Impact Analysis. Presentation at the Northwest Transportation Conference, Corvallis, OR.

DKS Associates. 2007. Boardman Interchange Area Management Plans and Transportation System Plan Update. June 2007.

Deen, T.B. 2003. Policy versus the market: Transportation's battleground. Transportation Research Record: Journal of the Transportation Research Board, No. 1839, 5-22.

Doering, W.W. 1977. Property tax equalization and conventional measures of assessment performance. In R.C. Denne (ed.), Analyzing Assessment Equity. Kansas City, MO: International Association of Assessing Officers, 23-41.

Dolan v. City of Tigard. 1994. 114 S. Ct. 2309, 129 L. Ed. 2d 304, 62 U.S.L.W. 4576.

Downs, A. 2003. Why Florida's concurrency principles do not - and cannot - work effectively. Transportation Quarterly, 57, 13-18.

Downs, A. 1962. The law of peak-hour expressway congestion. Traffic Quarterly, 16, 393-409.

Downs, A. 1957. An Economic Theory of Democracy. New York, NY: Harper.

Draper, R.W. 1987. A closer look at impact fees. Transportation Research Record: Journal of the Transportation Research Board, No. 1107, 68-73. 
Dueker, K.J., Rufolo, A.M. and C. Lawson. 1993. Congestion Management: Travel Behavior and the Use of Impact Fees. Volume II: Traffic Impact Fees: Issues Regarding Calculation and Efficiency. Final Report 93-06.2. Center for Urban Studies, Portland State University. Prepared for Transportation Northwest.

Ewing, R. 1994. Transportation utility fees. Government Finance Review, 10:4. Accessed at http://findarticles.com/p/articles/mi_hb6642/is_n3_v10/ai_n28645818/?tag=content;col1 July 10, 2009.

Federal Highway Administration. 2007. SIB highlights. Innovative Finance Quarterly. Washington, DC: U.S. Department of Transportation, author. Accessed at http://www.fhwa.dot.gov/innovativefinance/ifqwintr07.htm\#sib_highlights November 4, 2009.

Federal Highway Administration. 2002. State Infrastructure Bank Review. Washington, DC: author. Accessed at http://www.fhwa.dot.gov/innovativefinance/sibreview/index.htm December 12, 2009.

Federal Highway Administration. 1992. Fuel Tax Evasion: The Joint Federal/State Motor Fuel Tax Compliance Project. Washington, DC: U.S. Department of Transportation, author.

Forkenbrock, D.F. 2006. Financing local roads: Current problems and new paradigm. Transportation Research Record: Journal of the Transportation Research Board, No. 1960, 814.

Freilich, R.H. and S.M. White. 1994. Access Management and Land Use Planning: Integrating Regulatory and Structural Solutions to Traffic Congestion and Urban Mobility. Access Management Seminar, New York State Department of Transportation, Government Law Center of Albany Law School, May 3,1994.

French Development Agency and Ministry of Ecology, Energy, Sustainable Development and the Sea. 2009. Who Pays What for Urban Transport: Handbook of Good Practices. Paris, FR: authors.

Goldman, T. and M. Wachs. 2003. A quiet revolution in transportation finance: The rise of local option transportation taxes. Transportation Quarterly, 57:1, 19-32.

Greene, D.L. 1997. Why CAFÉ worked. Energy Policy, 26, 595-613.

Henken, T. 2009. NCHRP Synthesis 395: Debt Finance Practices for Surface Transportation. Washington, DC: National Cooperative Highway Research Program, Transportation Research Board of the National Academies.

Huang, H. 1996. The land-use impacts of urban rail transit systems. Journal of Planning Literature, 11, 17-30.

Joint Southeast Public Improvement Association. No Date. Memorandum. Englewood, CO. 
Kittelson and Associates, Inc. 2005. North Ontario Interchange Area Management Plan, Volume 1. Prepared for The Oregon Department of Transportation, Region 5. March 2005.

League of Oregon Cities. 2007. Implementing a Local Gas Tax: A Survey on City Gas Tax Ordinances. Salem, OR: author.

Lee, D.B. 1988. Evaluation of impact fees against public finance criteria. In A.C. Nelson (ed.), Development Impact Fees. Chicago, ILL: Planners Press, American Planning Association.

Leithe, J.L. and M. Montavon. 1990. Impact Fee Programs: A Survey of Design and Administration Issues. Government Finance Research Center of the Government Finance Officers Association, Washington, DC. (as described in "Traffic Impact Fees: Issues Regarding Calculation and Efficiency” by Dueker, Rufolo \& Lawson).

Levine, J.C. 1994. Equity in infrastructure finance: When are impact fees justified? Land Economics, 70:2, 210-222.

McCourt, R.S. 2006. Oregon's transportation planning rule goes into the shop for repairs. Transportation Research Record: Journal of the Transportation Research Board, No. 1981, 5659.

Missouri Department of Transportation. 2009. Transportation Corporations. Accessed at (http://www.modot.org/partnershipdevelopment/documents/TransportationCorporationInfo.pdf) April 1, 2009.

Murphy, E. and R. Bartlett. 2000. Have you considered a transportation utility fee? In League of Oregon Cities, LOCal Focus, June.

Musgrave, R.A. and P.B. Musgrave. 1989. Public Finance in Theory and Practice, Fifth Edition. New York: McGraw-Hill Book Co.

National Council for Public-Private Partnerships. 2009. The Highway 63 Transportation Corporation. Arlington, VA: author. Accessed at http://www.ncppp.org/cases/hwy63.shtml on November 23, 2009.

National Surface Transportation Infrastructure Financing Commission (NSTIFC). 2009. Paying Our Way: A New Framework for Transportation Finance. Washington, DC: author.

Nelson, A.C. 1988. Development impact fees. Journal of the American Planning Association, 54:1, 3-6.

Nelson, A.C., Lillydahl, J.H., Frank, J.E., and J.C. Nicholas. 1992. Price effects of road and other impact fees on urban land. Transportation Research Record: Journal of the Transportation Research Board, No. 1305, 36-41. 
Nicholas, J.C., Nelson, A.C., and J.C. Juergensmeyer. 1991. A Practitioner's Guide to Development Impact Fees. Chicago, IL: Planners Press, American Planning Association.

Nicholas, J. C. and A.C. Nelson. 1988. Determining the appropriate development impact fee using the rational nexus test. Journal of the American Planning Association, 54:1, 56-66.

Nollan v. California Coastal Commission. 1987. 483 U.S. 825, 107 S. Ct. 3141, 97 L. Ed. 2d 677.

Olson, M. 1965. The Logic of Collective Action: Public Goods and the Theory of Groups. Cambridge, MA: Harvard University Press.

Oregon Department of Revenue. 2009. A Brief History of Oregon Property Taxation. Salem, OR: author.

Oregon Department of Revenue. 2007. Urban Renewal. Salem, OR: author.

Oregon Department of Transportation (ODOT). 2008. "Negotiated Mitigation Agreements.” Chapter 5 in Development Review Guidelines. Salem, OR: author.

Oregon Department of Transportation. 2009a. Project Information Paper: OR 214 at Evergreen Road Transit Facility Project. Salem, OR: Region 2, author.

Oregon Department of Transportation. 2009. Project Information Paper: I-5 @ OR 214 Interchange (Woodburn). Salem, OR: Region 2, author.

Oregon Department of Transportation. 2007. Oregon Transportation Infrastructure Bank Annual Report. Salem, OR: author.

Oregon Department of Transportation. 2006a. Interchange Area Management Plan Guidelines. Planning and Implementation Unit, Transportation Planning Section. Salem, OR: author.

Oregon Department of Transportation. 2006b. Woodburn Interchange: Interchange Area Management Plan: Interstate 5 (Pacific Highway) at Oregon 214/219. Final Report. Salem, OR: author. Accessed at http://www.oregon.gov/ODOT/HWY/REGION2/docs/area3/Woodburn_Interchange/Interchange _Area_Mgmt_Plan_FinalJune06.pdf

Oregon Department of Transportation. 1999. 1999 Oregon Highway Plan. Planning Section, Transportation Development Division. Salem, OR: author.

Oregon Revised Statutes. Accessed at http://www.leg.state.or.us/ors/, March 2009.

Oregonian. 2008. "Washington County Measure Would Raise Developers’ Traffic Fees.” September 25, 2008. 
Paglin, M. and M. Fogarty. 1972. Equity and the property tax: A new conceptual focus. National Tax Journal, 25, 557-565.

Persad, K., Walton, C.M. and P. Franco. 2008. Financing Tools and Partnerships for Rural and Semi-Urban Transportation Partnerships. Project 0-6034. Austin, TX: Center for Transportation Research, University of Texas at Austin.

Polk County and Oregon Department of Transportation. 2005. Rickreall Junction Transportation Facility Plan. Salem, OR: authors.

Portland Development Commission. Urban Renewal Areas. Accessed at http://www.pdc.us/ura/gateway.asp, March 2009.

Portland Development Commission. Interstate Urban Renewal Area. Accessed at http://www.pdc.us/ura/interstate/.asp, March 2009.

Portland Office of Transportation. 2009. "What is a Local Improvement District?” Accessed at http://www.portlandonline.com/TRANSPORTATION/index.cfm?a=82642\&c=35715, March 2009.

Powell, B., Stringham, E.P. and J. Estill. 2006. Taxing Development: The Law and Economics of Traffic Impact Fees. The Independent Institute Working Paper Number 65. The Independent Institute, Oakland, CA.

Puentes, R. and R. Prince. 2003. Fueling Transportation Finance: A Primer on the Gas Tax. The Brookings Institution Series on Transportation Reform. The Brookings Institution, Washington, DC.

Reinmuth, J.E. 1977. The measurement of vertical inequities in assessment practice. In R.C. Denne (ed.), Analyzing Assessment Equity. Kansas City, MO: International Association of Assessing Officers, 47-68.

Reno, A.T. and J.R. Stowers. 1995. NCHRP Report 377: Alternatives to Motor Fuel Taxes for Financing Surface Transportation Improvements. Washington, DC: National Cooperative Highway Research Program, Transportation Research Board of the National Academies.

Road User Fee Task Force. 2003. Report to the $72^{\text {nd }}$ Oregon Legislative Assembly on the Possible Alternatives to the Current System of Taxing Highway Use Through Motor Vehicle Fuel Taxes. Salem, OR: author.

Rosenbloom, S. 2009. The equity implications of financing the nation's surface transportation system. TRNews, 261 (March-April), pp. 3-9.

Singell, L.D. and J.H. Lillydahl. 1990. An empirical examination of the effect of impact fees on the housing market. Land Economics, Vol. 66, 82-92. 
Sjoquist, D.L. 2003. State and Local Finances Under Pressure. Northampton, MA: Edward Elgar Publishing.

Smith, J.J. and T.A. Gihring. 2006. Financing Transit Systems Through Value Capture: An Annotated Bibliography. Victoria Transport Policy Institute, Victoria, BC.

Smith, P.K. 2001. Financing the airport light rail line in Portland Oregon: A case study of public-private partnership. Journal of Structured Finance, 7, 54-67.

Springer, C.D. and J. Ghilarducci. 2004. Transportation utility fee: Oregon experience. Transportation Research Record: Journal of the Transportation Research Board, No. 1895, TRB, National Research Council, Washington, D.C., 2004, pp. 15-24.

Strathman, J.G., Kimpel, T.J., Leistner, P., and K.J. Dueker. 2005. Comprehensive Plan Amendment Impacts on Interchanges in Oregon. Final Report SR 500-131, Research Unit, Oregon Department of Transportation, Salem, OR.

Tollroadnews. 2007. "Florida's Turnpike Opening Another Transponder-Only Interchange Funded by Developers,” May 9, 2007. Accessed at http://www.tollroadnews.com/node/128 on November 28, 2009.

Transportation Research Board (TRB). 2006. Special Report 285: The Fuel Tax and Alternatives for Transportation Funding. Washington, DC: author.

URS Corporation. 2009. Draft Interchange Area Management Plan: I-5 Fern Valley Interchange. Prepared for the Oregon Department of Transportation and the City of Phoenix, July.

U.S. Bureau of the Census. 1982. Census of Governments 1982, Volume 2: Taxable Property Values and Assessment-Sales Price Ratios. Washington, DC: U.S. Department of Commerce, author.

Vadali, S.R., Aldrete, R.M. and A. Bujanda. 2009. Financial model to assess value capture potential of a roadway project. Transportation Research Record: Journal of the Transportation Research Board, No. 2115, pp. 1-11.

Wachs, M. 2003. Improving Efficiency and Equity in Transportation Finance. The Brookings Institution Series on Transportation Reform. The Brookings Institution, Washington, DC.

Williams, K.M. 2006. Alternative Funding Strategies for Improving Transportation Facilities: A Review of Public-Private Partnerships and Regulatory Methods. Prepared for North Carolina Department of Transportation. Center for Urban Transportation Research, University of South Florida, Tampa, FL.

Winston, C. 1991. Efficient transportation infrastructure policy. Journal of Economic Perspectives, 5:1, 113-127 